This item was submitted to Loughborough's Research Repository by the author.

Items in Figshare are protected by copyright, with all rights reserved, unless otherwise indicated.

\title{
Fintech and the future of financial services: What are the research gaps?
}

\section{PLEASE CITE THE PUBLISHED VERSION}

https://crawford.anu.edu.au/publication/cama-working-paper-series/13805/fintech-and-future-financialservices-what-are-research

\section{PUBLISHER}

Crawford School of Public Policy

\section{VERSION}

NA (Not Applicable or Unknown)

\section{PUBLISHER STATEMENT}

This work is made available according to the conditions of the Creative Commons Attribution-NonCommercialNoDerivatives 4.0 International (CC BY-NC-ND 4.0) licence. Full details of this licence are available at: https://creativecommons.org/licenses/by-nc-nd/4.0/

\section{LICENCE}

CC BY-NC-ND 4.0

\section{REPOSITORY RECORD}

Kavuri, Anil Savio, and Alistair Milne. 2019. "Fintech and the Future of Financial Services: What Are the Research Gaps?". figshare. https://hdl.handle.net/2134/36938. 


\title{
CAMA
}

Centre for Applied Macroeconomic Analysis

\section{FinTech and the future of financial services: What are the research gaps?}

\section{CAMA Working Paper 18/2019 February 2019}

\section{Anil Savio Kavuri}

School of Business and Economics, Loughborough University

Centre for Applied Macroeconomic Analysis, ANU

\author{
Alistair Milne \\ School of Business and Economics, Loughborough University
}

\section{Abstract}

New financial technologies (FinTech) have erupted around the world. Consequently, there has been a considerable increase in academic literature on FinTech over the last five years. Research tends to be scantily connected with no coherent research agenda. Significant research gaps and important questions remain. There is much work to be done before this area becomes an established academic discipline. This paper offers coherent research themes formulated through focus group meetings with policymakers and academics, and also based on a critical assessment of the literature. We outline seven key research gaps with questions that could form the basis of academic study. If these are addressed it would help this area become an established academic discipline. 


\section{Keywords}

FinTech, industrial structure, customer benefits, barriers, vulnerable customers, identity, cyber security, Al, financial stability, regulation cryptocurrencies, payments, business models, Bitcoin, Blockchain

\section{JEL Classification}

E58, G18, G20, G21, G28, G29, K12, K24, O30, O32, O33

\section{Address for correspondence:}

(E) cama.admin@anu.edu.au

ISSN 2206-0332

The Centre for Applied Macroeconomic Analysis in the Crawford School of Public Policy has been established to build strong links between professional macroeconomists. It provides a forum for quality macroeconomic research and discussion of policy issues between academia, government and the private sector.

The Crawford School of Public Policy is the Australian National University's public policy school, serving and influencing Australia, Asia and the Pacific through advanced policy research, graduate and executive education, and policy impact. 


\title{
FinTech and the future of financial services: What are the research gaps?
}

\author{
Anil Savio Kavuri and Alistair Milne *
}

February 9, 2019

\begin{abstract}
New financial technologies (FinTech) have erupted around the world. Consequently, there has been a considerable increase in academic literature on FinTech over the last five years. Research tends to be scantily connected with no coherent research agenda. Significant research gaps and important questions remain. There is much work to be done before this area becomes an established academic discipline. This paper offers coherent research themes formulated through focus group meetings with policymakers and academics, and also based on a critical assessment of the literature. We outline seven key research gaps with questions that could form the basis of academic study. If these are addressed it would help this area become an established academic discipline.
\end{abstract}

JEL Codes: E58, G18, G20, G21, G28, G29, K12, K24, O30, O32, O33,

\footnotetext{
*Kavuri: Crawford School of Public Policy, Australian National University, Australia and School of Business and Economics, Loughborough University, UK. Email: a.s.kavuri@lboro.ac.uk. Milne: School of Business and Economics, Loughborough University, UK. Email:A.K.L.Milne@lboro.ac.uk.
} 
Key words: FinTech, industrial structure, customer benefits, barriers, vulnerable customers, identity, cyber security, AI, financial stability, regulation cryptocurrencies, payments, business models, Bitcoin, Blockchain

\section{Introduction}

FinTech has risen dramatically with cumulative investment of $\$ 100$ bn by newcomers since 2010 (Accenture 2018). Incumbents has also spent dramatically at $\$ 450$ bn annually. Consequently, over the last five years, there has a considerable increase in academic literature on the subject. However, it is not an established area of research. Furthermore, the literature is loosely connected with no overall research agenda.

The goal of this paper is to provide a critical assessment of the literature, highlight research gaps and structure coherent research agendas to provide a foundation for future scholarly work and policy decisions. We have located and reviewed over one hundred articles, book chapters and working papers on financial technology (FinTech). This paper has analysed research within nearly all fields including economics, business and other social science disciplines, applied engineering and computer science. In addition, we have consulted with academics, practitioners and policymakers in formulating our research agendas and gaps.

This paper is organised around seven research gaps which are 1) changing industrial structure and organisation of financial services, 2) new forms of financial intermediation (alternative finance) such as loan-based and equity-based crowdfunding, 3) changing payments mechanisms including central bank digital currencies and the shift to a cashless society, 4) reaching vulnerable and excluded customers in both developed and developing countries, 5) computation, artificial intelligence and large-scale data processing in finance, 6) the relationship between 
the new financial technologies and financial regulation, 7) identity, security, data privacy and their regulation in financial services.'The relationship between the new financial technologies and financial regulation' includes a number of themes. Consequently, we categorise it into three critical areas i) FinTech and financial stability; ii) policy and the role of government iii) RegTech. This paper also provides a review of 'cryptofinance-radical technology-based alternatives to conventional regulated financial services'. This area is separated from FinTech for two main reasons. Firstly, research has covered this area extensively unlike the other seven areas. Secondly, it is a form of finance that uses pseudo-anonymity and cryptographic security to operate outside of the regulated industry. The research in the other categories is in relation to the application of new technologies in regulated financial services.

The rest of paper is structured as follows. In the next section, we provide a selection of descriptive papers. Although these are mainly consulting reports, they offer an informative overview of the FinTech market. After which the research gaps are highlighted in sections 3 through 9. Section 10 includes research on cryptofinance. Section 11 concludes.

\section{Descriptive analysis}

There are numerous descriptive papers, predominately undertaken by consulting reports. These emphasis the substantial growth in the FinTech market.

PWC is a global FinTech report produced by PWC in 2017. It draws on their global survey of 1) 1,308 financial services and FinTech executives, and 2) their proprietary data from PwCs DeNovo platform. Some useful points are raised. For instance, participants expect $20 \%$ ROI annually on FinTech related projects globally (in Asia $25 \%$, North America 23\%, Latin America 22\%, Africa 18\%, Oceania 
$16 \%$ and Europe 14\%). Insurers are more conservative than financial institutions with a $13 \%$ expected return. In addition participants believe the following are regulatory barrier to innovation (brackets are $\%$ of participants) 1) data storage (54\%), 2) digital identity authentication (50\%), 3) AML/KYC (48\%), 4) new business models-crowdfunding, P2P (40\%), 5) E-money/cryptocurrency (30\%). 82\% of responded expect to increase partnerships with FinTech companies over the next three to five years.

Jonsdottir et al. (2017) is a Deloitte study focusing on the significant growth of FinTech in the Nordic countries. It highlights that Sweden has led the way in the market of the Nordics in terms of investments with 50 individual investments made from January 2014 until time of the Deloitte study. Other Nordics are picking up pace. The dominance of Sweden is explained by available finance and easy access to education. The development of the Nordic FinTech market is based on four key drivers; regulation, talent, capital and collaboration. Deloitte (2017) is another consulting report but focuses on managing conduct risk. A section of the report consider how FinTech and RegTech could be used to address the drivers of poor conduct, assist to manage conduct risk and provide consumer benefits. The innovative solutions for managing conduct risk include technology 1) that tests cultural values, 2) that automates monitoring, 3) that streamlines procedures, 4) that helps to integrate teams, 5) that strengthen accountability, 6) that proactively identify and manage conflicts. The report highlights examples of recent disruptive technologies including 1) robotic process automation is allowing software robots to perform routine business processes, 2) advanced analytic techniques allow meaningful insights to be gleaned from huge pools of data etc.

Dorfleitner et al. (2017) provides another regional study with an analysis of German FinTech industry. Dorfleitner et al. (2017) calculates that in 2015 the total market volume of FinTech businesses in Germany in the financing and wealth 
management segments was 2.2 billion EUR. A major part of crowdfunding (270 million EUR), and wealth management is dominated by social trading and roboadvice platforms (360 million EUR). The paper suggests that the FinTech industry does not currently represent a systemic risk to the German economy. Note that after the UK, Germany is the second largest FinTech market in Europe. The study points out that FinTechs can help to reduce the funding gaps of small and medium-sized enterprises (SMEs) in Europe. Banks differ in supply of products offered by FinTech firms. Most banks have as of yet scarcely explored crowdfunding solutions. They point out that as a general rule only SME make use of rewards-based crowdfunding. Those that have high R\&D investment is particularly suitable, which is $2 \%$ of the market. The market is estimated at 4.6 Billion EUR.

Before we begin the research gaps in the next section, it is informative to highlight that several quantitative studies offer statistical evidence on the reasons for the emergence of FinTech (Haddad and Hornuf 2016; Buchak et al. 2017; Shim and Shin 2016). Haddad and Hornuf (2016) and Buchak et al. (2017) are economic regression analysis. For instance, Buchak et al. (2017)'s empirical analysis suggests that regulatory burden faced by traditional banks accounted for $70 \%$ of shadow bank growth with financial technology accounted for $30 \%$. Shim and Shin (2016) use an actor-network theory based on the science and technology literature to investigate the factors contributing to the growth of Chinas FinTech industry. Cumming and Schwienbacher (2016) examine determinants of FinTech venture capital (VC) investment finding (somewhat surprisingly) that FinTech venture capital (VC) investments are more prominent in countries without a financial centre. 


\section{Gap one: Changing industrial structure and organisation of financial services}

The first research agenda is to investigate the process and structure of change in the financial industry arising from new technologies. Studies that formulate analytical frameworks for understanding these changes and empirical work is lacking. In addition, most current studies focus on the short run without any detailed analysis in the medium and long run. There is a clear gap in adopting interviews, empirical analysis and comparison case studies-historical and international.

Dhar and Stein (2016) is a good base as they investigate the impacts of FinTech innovation on the incumbent and new business models. They provide a framework for understanding the value created through various types of platforms in financial services. The framework provides a way to understand the winners and losers in the industry. They offer a number of platforms with only complete platforms containing the 3 attributes of 1) openness of access, 2) functionality embedded in an IT system, and 3) implementation of standardized domain-specific business processes. The framework provides a way to understand which businesses are vulnerable due to their incompleteness. FinTech platform completion strategies can potentially disrupt any of the incomplete platform models.

Gomber et al. (2018) goes down a different angle and develop a FinTech innovation mapping approach to determine the extent to which there are changes and transformations in areas of the financial service industry. The main conclusions are 1) incumbents will find it difficult to compete with small entrepreneurial start-ups, hence better to outsource applications, 2) FinTech sector is likely to experience significant adjustment, 3) research agenda can deliver important insights. They highlight a number of questions that could be addressed in future research. These include, 1) what will be the drivers of success among FinTech start-ups?, 
2) will knowledge spill over into other areas of business involving technology?, 3) will there be globalization or agglomeration of the FinTech industry?, 4) How will the business models, operations, and microstructure of leading financial markets be affected?, 5) how will RegTech innovations come into the industry?

Although Van Alstyne, Parker, and Choudary (2016) is not specifically on FinTech, the paper is relevant. Van Alstyne, Parker, and Choudary (2016) investigate the changing rule of strategy. They highlight the success of iPhone in dismantling the power of the five major mobile-phone manufacturers. They suggest change is need from pipeline to platform, from internal optimization to external interaction, from a focus on customer value to a focus on ecosystem value for success. The paper highlight that network effects are the driving force behind every successful platform. They finally discuss that platforms change due to forces exerted by ecosystems, business focus, governance and harnessing spillovers among others.

Kazan et al. (2018) investigates platform competition using the UK mobile payment market as an empirical case study. They use a comparative analysis of mobile payment services to determine attributes along the dimensions of value creation and delivery through which these FinTechs innovate. Mobile payment platforms could be defined 1) whether they are integrative or integratable on their value creation and 2) whether they have direct, indirect, or open access on their value delivery architecture. Using these attributes, they characterise mobile payment services into six platform profiles. These aided the development of a competitive strategy associated with each profile. The three types of platform competitive strategies are 1) Germination Strategy, 2) Orchestration Strategy, 3) Transformation Strategy.

Lacasse et al. (2016) look at business models. The paper investigates the elements of successful FinTech business models. Qualitative data (i.e., classical ethnography to state and governmental studies, documentary evidence, local case 
studies, participant observation, semi-structured interviews etc.,) provides the conceptual representation for their business models. FinTech utilises the new digital technologies offering convenient banking products that cost less. They also go around regulatory compliance and focus on a user-friendly single-purpose solution. The papers end with a number of research agendas including How does FinTech create value? How will smarter and faster machines transform capital markets? What is the social return on investment (SROI) of the FinTech industry?

Regarding impact, Elliott et al. (2016) suggests that distributed ledger technologies, blockchains and cryptographically enabled contracts are more than just disruptive technology for the financial sector but are 'hyper-disruptive' technology that transforms the economic foundation of organizations.

Gozman, Liebenau, and Mangan (2018) classify the characteristics of the global FinTech landscape. They use a cluster analysis to group 402 FinTech start-ups that participated in SWIFT's Innotribe competition. The clusters are FinTech's core services, business infrastructures and the FinTech's foundational component technologies. In addition, they analyse how FinTech's synthesize technologies and strategies for value creation.

In summary, although these papers are a good basis, this section has revealed numerous gaps that has yet to be addressed. For instance, 1) what products and services can be competitively provided by FinTech companies?, 2) will this dismantle the competitive advantage of incumbents? Furthermore, there is an opportunity to develop detailed analytical frameworks and undertake empirical work to understand the changing structure and organisation of financial services resulting from FinTech. 


\section{Gap two: New forms of financial intermedi- ation (alternative finance) such as loan-based and equity-based crowdfunding}

Crowdfunding are financial platforms that support direct holding of small investments in equity and debt, as an alternative to intermediation through banks and investment intermediaries. There is much research that uses the data from loanbased and equity-based crowdfunding to undertake a specific study. The range of topics studied is extremely large. However, there is no detailed work on how alternative finance is transforming business models. Our focus group revealed that this is major gap that need to be addressed. In this section, we categorise the research into 4.1 equity-based crowdfunding and 4.2 loan-based crowdfunding.

Before we begin, it is informative to provide an overview of the market. Wardrop et al. (2015) provides a relevant discussion by using their own created database. The University of Cambridge partnered with EY and 14 leading national/regional industry associations to collect industry data from 255 leading platforms in Europe through a web-based questionnaire. This captures an estimated 85-90\% of the European online alternative finance market. Wardrop et al. (2015) investigate online alternative finance across Europe (France, Germany, Netherlands, Spain, Nordic countries, UK ). The report highlights the considerable variation in how alternative finance is developing across Europe. Important facts highlighted in the document include 1) European alternative finance market, excluding the UK, is estimated to have provided 10,000 European start-ups and SMEs an aggregate of $385 \mathrm{~m}$ euros in the last 3 years (the book is written in 2015). 201.43m euros was funded in 2014 alone. 


\subsection{Equity-based crowdfunding}

A significant amount of work has been on investors' decisions to invest (Cholakova and Clarysse 2015; Hornuf and Schwienbacher 2017; Babich and Hilary 2018; Vismara 2016) and/or reasons for borrowers' success in obtaining funds( Colombo, Franzoni, and Rossi-Lamastra 2015; Moss, Neubaum, and Meyskens 2015; Ahlers et al. 2015).

Cholakova and Clarysse (2015) investigate the financial and nonfinancial motivations that determine the decision to invest for equity or to pledge on crowdfunding platforms. The paper surveyed all registered investors (454) on the largest equity crowdfunding platform in the Netherlands, Symbid. The number of respondents was 155. They found that nonfinancial motivations do not play a significant role. In addition, individuals having invested for equity is a positive predictor of pledge.

Hornuf and Schwienbacher (2017) argue too strong investor protection in equity financing may harm small firms. They discuss regulatory reforms in various countries (USA, Italy, Austria, UK, France, Belgium and Germany) and their potential impact on equity crowdfunding. Using a theoretical framework that is based on managerial rent diversion they show that optimal regulation depends on the availability of an alternative early-stage financing. The evidence is provided in Germany.

Babich and Hilary (2018) explore the impact of provision points in crowdfunding. The research tackles the following questions 1) Does the use of a provisionpoint mechanism amplify or attenuate the effects of prior capital accumulation on visitor conversion and contribution decisions? 2) How do these effects vary over the fundraising lifecycle? They use a sample of 250,000 campaign URL visits collected over a 3 month period at the end of 2012 and beginning of 2013. The study finds that provision points weaken the association between prior capital accumulation 
and visitor contribution. Consequently, this implies a reduction in herd behaviour.

Vismara (2016) investigates the impact of equity retention and social capital as a signal to investors. The data is of 271 projects listed on the UK platforms Crowdcube and Seedrs from 2011 to 2014. The paper finds that entrepreneurs had higher success probabilities when they 1) sold a smaller fraction of their companies and 2) had more social capital.

Colombo, Franzoni, and Rossi-Lamastra (2015) investigate whether social capital helps to attract contributions in the very early days under conditions of maximum uncertainty. The paper shows that crowdfunding platforms allow users to highlight their external social capital and stock of social capital built within the crowdfunding platform. Econometric analysis of a sample of 669 Kickstarter projects shows a self-reinforcing success mechanism.

Ahlers et al. (2015) empirically investigate the effectiveness of signals that induce investors to provide financial resources in equity crowdfunding. The data is obtained from ASSOB, the Australian platform ( in business since 2006). The time period is between October 2006 and October 2011 and includes 104 equity crowdfunding offerings. Impact of human capital, social capital, intellectual capital and uncertainty on fundraising success is investigated. Social capital and intellectual capital has a limited impact on funding success. Retaining equity and providing more information on risks strongly influence funding success probability.

Moss, Neubaum, and Meyskens (2015) argue that narratives of microenterprises on microfinancing platforms are an important way to signal characteristics and behavioural intentions to lenders. The sample is of 400,000 loans made to entrepreneurs who use the microfinance crowdfunding platform Kiva to access capital for their ventures from 2006 to 2012. Kiva lenders are more likely to fund ventures that signal autonomy, competitive aggressiveness, and risk-taking. In contrast conscientiousness, courage, empathy, and warmth are less likely to obtain funding 
(note that rhetorical signalling of these are negatively associated with loan payment).

The topics outside investors' decisions to invest and/or reasons for borrowers' success are wide. For instance, Rau (2017) investigates the determinants of crowdfunding. He uses a hand-collected sample of crowdfunding volume obtained by a worldwide survey of over 1,300 crowdfunding platforms. The data is of only one year, 2015. He models transaction volume as a function of three economic factors: barriers to entry, the financial profitability of incumbents, and financial potential. He also includes regulatory climate and country propensity. For each factor, he uses various indicators. For example, he argues potential financial depth is individuals access to the market, which he measures with a Global Competitiveness Report and another report from the GFDI database. He finds that barriers to entry and potential financial depth is important in explaining financing volume. Rule of law is also important. However, there is no support for type of legal regime, civil and common law in explaining the volume or type of crowdfunding patterns. Extant intermediaries financial profitability and the extant financial depth are not significant.

Schwienbacher and Larralde (2010) is an early paper on crowdfunding. They highlight various business models based on the different type of rewards that are offered to the participating crowd. The rewards offered include donations, passive investments by the crowd and active investments by the crowd. They then investigate a case study, Media No Mad to discuss their analysis.

Belleflamme, Lambert, and Schwienbacher (2014) compare two forms of crowdfunding 1) entrepreneurs solicit individuals to pre-order the product, 2) to advance a fixed amount of money in exchange for a share of future profits (or equity). In both cases, crowdfunders obtain community benefits that increase their utility. The paper shows that the entrepreneur prefers pre-ordering if the initial capital 
requirement is small compared with the market size and prefers profit sharing if not.

Chemla and Tinn (2017) examine why crowdfunding is particularly attractive for innovative projects. The develop a theoretical model where crowdfunding enables firms to learn about total demand from a sample of target consumers preordering a new product. Learning creates a valuable real option particularly for firms facing a high level of consumer preferences uncertainty. They argue crowdfunding play important role in allowing firms to test out markets.

Johnson, Stevenson, and Letwin (2018) argue that previous research shows that female entrepreneurs are disadvantaged when compared to male entrepreneurs by banking financing, private equity financing and institutional capital. However, this study's empirical analysis shows that in crowd financing there is a funding advantage for women. To understand the reasons for the empirical results they use stereotype content theory and test a dual path moderated-mediation model. They find that amateur investors perceive female entrepreneurs as more trustworthy than male entrepreneurs.

Wonglimpiyarat (2018) examines FinTech crowdfunding in the Thai financial innovation system under the policy direction of 'Thailand 4.0'. The paper uses the national innovation system (NIS) to undertake the qualitative analysis. The paper draws on 30 interviews and documentary evidence. Crowdfunding is not popular in Thailand. Potential fraud is an issue. They argue that most interviewees suggest that the Ministry of Digital Economy and Society should devise policies to support crowdfunding, protect start-ups and reduce obstacles to SME.

Agrawal, Catalini, and Goldfarb (2011) investigate crowdfunding for financing musical projects. The average distance between artist-entrepreneur and investor is 3,000 miles. They demonstrate that the geography effect is reduced. Any effect is likely to be due to a personal connection between the investor and the 
artist-entrepreneur. Online platform reduce majority of distance-related economic frictions, but not social-related frictions.

Agrawal, Catalini, and Goldfarb (2014) is a discussion paper based on economic theory. The paper uses concepts of transaction costs, reputation, and market design to explain nonequity crowdfunding. Their framework can be used to understand the success and outcomes of equity-based crowdfunding. The analysis includes discussion of incentives and disincentives of three primary actors in crowdfunding 1) creators, 2) funders, and 3) platforms.

\subsection{Loan-based crowdfunding}

Most of loan-based crowdfunding research focus on success in obtaining loans (Lin, Prabhala, and Viswanathan 2009; Freedman and Jin 2017; Xu and Chau 2018 ) and/or interest rates and loan spreads paid (Iyer et al. 2009; Mach, Carter, and Slattery 2014; Faia and Paiella 2018; Jagtiani and Lemieux 2017;).

Lin, Prabhala, and Viswanathan (2009) investigate the online market for P2P lending in which individuals bid on unsecured microloans sought by other individual borrowers. Using a sample from the largest online P2P lending marketplaceProsper.com, they test whether social networks lead to better lending outcomes. They determine that stronger and more verifiable relational network measures are associated with a higher likelihood of a loan being funded, a lower risk of default, and lower interest rates.

Freedman and Jin (2017) study the impact of social networks assist on P2P lending using data from Prosper.com. They find borrowers with social ties are more likely to obtain loans and receive lower interest rates. They show that applicant's friends committing to invest in the loan is a greater signal in lower credit grades. However, most borrowers with social ties do not perform better ex-post.

$\mathrm{Xu}$ and Chau (2018) explore the implications of lender-borrower communica- 
tion on funding outcomes and loan performance in the P2P market. The research determines 1) whether communication matters, (2) whether lender's decisions are impacted by other lenders' opinions and (3) whether the quality of information provided by borrowers makes lenders trust borrowers. In addition, they answer whether the communication is a forecaster of loan defaults. They study the platform, LendingMarket (one of the largest P2P lending marketplaces in China). Two dependent variables are used to represent funding outcomes 1) funding success 2) final interest rate. They find that the more comments a listing receives, the less likely the listing will get funded. However, the more responses a borrower makes to the comments, the more likely the listing will obtain funding.

Iyer et al. (2009) investigate empirically whether lenders can use borrowers soft information to infer creditworthiness as a screening tool in P2P markets. They determine that lenders are able to use the information to infer a third of the variation in creditworthiness that is captured by a borrowers credit score. This inference is economically significant and allows lenders to lend at a 140-basis-points lower rate for borrowers with (unobserved to lenders) better credit scores within a credit category.

Mach, Carter, and Slattery (2014) using data from the LendingClub's platform shows that small business paid higher rates through P2P than from traditional banks.

Faia and Paiella (2018) investigate the impact of information externalities on loans' spreads. They use data from Prosper and Lending Club to undertake their regressions. Hard information signals, such as FICO scores and other creditworthiness measures are included. Soft information signals such as recommendations and investment from 'groups of friends', and a liquidity risk indicator in the traditional banking sector (ratio of currency in the hand of the public to demand deposits) are also included. Their empirical analysis shows that loans' spreads (asymmetric 
information) decline with credit scores and 'group ties' indicators. Furthermore, they find that increased bank fragility risk in the traditional banking sector increases P2P markets participation and reduces their rates (substitution effect).

Jagtiani and Lemieux (2017) study the advantages/disadvantages (e.g., financial inclusion, default) of loans made by a large FinTech lender and similar loans that were originated through traditional banking avenues. They use Lending Club's account-level data and Y-14M bank stress test data. They show that Lending Clubs consumer lending activities have penetrated areas that could benefit from additional credit supply (e.g. areas that lose bank branches and those in highly concentrated banking markets). The rating grades have a decreasing correlation with FICO scores and debt-to-income ratios which suggests that alternative data is being used and performing well. Lending Club borrowers are, on average, riskier than traditional borrowers given the same FICO scores. Alternative information sources have allowed borrowers who would be classified as subprime by traditional criteria to obtain better loan grades and therefore get lower priced credit. Furthermore, for the same risk of default, consumers pay smaller spreads on loans from the Lending Club than from traditional lending channels.

Other studies analyse a specific topic. Jagtiani and Lemieux have contributed many studies. For instance, Jagtiani and Lemieux (2016) examine the decline in small business lending among U.S community banks. Using Federal Reserve data, they show that prior to the financial crisis, small business used real estate as collateral for loans. Community bank's credit reduced during the crisis. After the crisis, large banks used technology to compete for smaller borrowers. They also study alternative lenders, those that issue loans electronically, across a range of borrowers risk profile. They also look at the potential that community banks may gain background by linking up with alternative lenders. Note that Jagtiani and Lemieux (2018) point out that Mach, Carter, and Slattery (2014) used definitions 
from LendingClub's platform of small business purposes that are not comparable with small business loans from traditional banks.

Jagtiani and Lemieux (2018) find that LendingClub's consumer lending activities have penetrated areas that highly concentrated banking markets and other areas that have fewer bank branches per capita (i.e., a smaller number of bank branches to serve a larger number of local potential borrowers).

An interesting study into financial inclusion is Havrylchyk et al. (2017). The paper explores three of their hypothesis about the expansion of P2P lending which includes 1) global financial crisis, 2) nature of banking in regards to barriers to entry, 3) switching costs. They use Maximum-Likelihood Estimator method to compute the cross-sectional spatial regressions. They find that online lenders have expanded into counties with a poor branch network and lower bank concentration. They argue that these borrowers may live far away from a physical bank branch or have a poor branch experience. Higher education has a positive impact.

Jiang et al. (2018) investigate how various platform attributes and regulations impact investor's herding behaviour in the $\mathrm{P} 2 \mathrm{P}$ lending market in China. They used weekly panel data set from 127 P2P leading platforms over 44 weeks. They find that herding exists at the platform level. They also explore the impact of platform attributes and government regulations. Utilising a multilevel mixed-effects model, they find that herding behaviour is amplified by platforms market share and the cumulative amount funded, however, reduced by their time in operation. Government regulation (i.e. regulations on P2P operational standards, principles, and supervisory details) reduced the magnitude of herding.

Milne and Parboteeah (2016) argue that P2P lending is complementary to conventional banking. The paper suggest that banks will cooperate with thirdparty P2P lending platforms or offer own proprietary platforms. To ensure viable development of the sector requires regulatory problems (i.e., transparent and stan- 
dardisation of regulation and business risks in P2P lending to be addressed. These include 1) risk communication, 2) resolution of platform failure, 3) control of liquidity risks, 4) minimisation of fraud, 5) security and operational risks. The paper provides an analysis of 1) the development of P2P lending, 2) P2P lending markets (i.e., EU, China, US etc.,), 3) business models and economics of P2P lending, 4) regulation.

Borrower's success, rates and lenders willingness to invest are the main themes. Apart from this topics are wide spread. However, there are many questions that are still unanswered these include: How will these platforms change business models? Will these new platforms capture a significant share of incumbents customer base? Will these platforms co-operate with incumbents in sharing services? Addressing these questions would form a solid research agenda.

One study which makes has made an initial attempt at addressing these questions is Milne (2018a). Milne (2018a) utilizes interviews with platform operators in the UK and Australia to examine the regulation, governance and business strategy of marketplace lending platforms. The two main questions addressed by the interviews are 1) what business models are being applied by marketplace lending platforms and would they develop in the medium to long term? 2) is regulation viable for these and competitors business models? The main contribution of the paper is the identification of sixteen different component activities involved in marketplace lending which is the framework foundation to analyse benefits of regulation. Using the developed framework, the paper suggests marketplace lending is complementary to conventional bank balance sheet intermediation. Consequently, a functional approach to regulation is optimal to promote better consumer service. 


\section{Gap three: Changing payments mechanisms including central bank digital currencies and the shift to a cashless society}

There is a significant gap in investigating payments platforms, competition and consumer attitudes to the payment systems. Work into state issued payments and commercial bank payments were highlighted as a key area from our discussions. Although, there is recent work into central bank digital currency, importantly there is little academic research into fraud, financial crime, identity and data infrastructure in regards to the changing payment mechanisms.

As suggested, the most covered studied area in this section is in relation to central bank digital money ( Fung and Halaburda 2016; Ketterer and Andrade 2016; Bordo and Levin 2017; Bjerg 2017; Constâncio 2017; Gouveia et al. 2017; Barrdear and Kumhof 2016; Callesen (2017); Meaning et al. 2018; Kumhof and Noone 2018; Milne 2018b).

Fung and Halaburda (2016) propose a framework for a central bank to determine whether to issue digital currency. Furthermore, they suggest how to implement CBDC to improve the efficiency of the retail payment system. The three public policy arguments for a central bank to consider when issuing a digital currency are 1) Would efficiency improve? , 2) Would privately issued digital currencies provide such efficiency improvements without government intervention?, 3) Is issuing a digital currency a role a government should play?

Ketterer and Andrade (2016) argue that central bank money (CBD) is likely to lead to unbundling of banking functions. The paper highlights the following risks 1) large amounts of CBD deposits takes away deposits from commercial banks limiting these ability to provide credit and hence impact economic activity, 2) decrease in the use of institutions with expertise in the provision of payment ser- 
vices, 3) intraday credit increased which may require the central bank to provide significant amounts of credit to less creditworthy institutions.

Bordo and Levin (2017) argue that a well-designed central bank digital currency (CBDC) should be 1) an account-based for CBDC to ensure costless medium of exchange. Accounts should be held directly at a central bank or available via public-private partnerships with commercial banks, 2) interest-bearing for CBDC to ensure a store of value. CBDC interest rate could be a tool for conducting monetary policy, 3) widely available to the public with a graduated schedule of fees on transfers between cash and CBDC to aid gradual obsolescence of paper currency, 4) stable over time in terms of a broad consumer price index, which would foster true price stability. CBDC could be a costless medium of exchange, secure store of value, and stable unit of account. However, there are some risks including 1) macroeconomic instability, 2) loss of monetary control, 3) systemic risks, 4) susceptible to severe downturns.

Bjerg (2017) evaluates three different scenarios for the implementation of CBDC in terms of their monetary policy implications including 1) CBDC co-exists with cash and commercial bank deposits, 2) CBDC co-exists only with commercial bank deposits (cash abolished), 3) CBDC co-exist only with cash (commercial bank deposits abolished). The analysis is based on monetary policy trilemma formulated for the domestic economy with multiple forms of money. Paper proposes for the central bank and the commercial banking sector to be money creators. Universal access to CBDC is suggested.

Constâncio (2017) argues that creation of digital currency by a central bank open to all citizens without limits would be very disruptive. Hence, it is unlikely. He believes FinTech is likely to be significantly transformative but disruptive.

Barrdear and Kumhof (2016) uses a DSGE model to show that real GDP could increase by $3 \%$ with the introduction of a Central Bank Digital Currency (CBDC). 
This results from reductions in real interest rates, distortionary taxes, and monetary transaction costs.

Callesen (2017) argues that a central bank providing a digital currency will not create something which is not already offered by private banks. However, open a highway to bank runs, challenging financial stability. Furthermore, he points out that problems including 1) competitive distortions, 2) IT staff costs, 3) regulatory compliance costs.

Kumhof and Noone (2018) explore the impact on the balance sheet of three models that differ in the sectors that are able to access CBDC. They suggest if 1 to 4 core principles then system-wide bank runs will be tackled, bank funding will not necessarily reduce and credit to the private sector will not contract. The principles include 1) CBDC pays an adjustable interest rate, 2) $\mathrm{CBDC}$ and reserves are not convertible, 3) no guaranteed convertibility of bank deposits into CBDC at commercial banks, 4) central bank issues CBDC only against eligible securities.

Meaning et al. (2018) explore the implications of CBDC on the monetary transmission mechanism-how a change in policy instruments leads to change in the path to the real economy. The paper argues that universally accessible, interest-bearing, account-based $C B D C$ can be used for monetary policy as central bank reserves are now. They argue that the monetary transmission mechanism would be stronger given policy instruments change.

Gouveia et al. (2017) explores the possibility of implementation and impact of four scenarios of CBDC. They consider the features of physical cash (i.e. P2P, universality, anonymity etc.,) in their analysis. Less disruptive scenarios are more likely. CBDC will be a mechanism for interbank settlement is most likely over the coming years. After which, CBDC will be created to be as similar to cash as possible. The paper argues that less disruptive scenarios for CBDC followed by more are optimal for implementation. 
Milne (2018b) examines whether governments will use cryptographic security technologies to support digital currencies? and if so what are the economic implications of this? The paper analyses 1) the possibility of state employment of cryptocurrency technology and the issue of cryptographically secured digital currencies, 2) economic benefits and costs of state issue of digital currencies, 3) whether more improvements can be obtained with cryptocurrency technologies (i.e., financial sector safer and more competitive). Four main central banks issue of digital currency is highlighted including 1) creation of the electronic equivalent of cash, 2) access to central bank liabilities for selected non-bank intermediaries, 3 universal access for all individuals and legal persons, 4) cryptographically based narrow banking proposal.

Agarwal (2015) study is related to government policy. They show how transitional electronic money system, paper currency in use and electronic money as the unit of account can enable below zero lower bound policy. Key point is that costs of inflation are costs of inflation only relative to the unit of account..

There are several relevant studies on payments modes (Mills et al. 2016 ;Parlour, Rajan, and Walden 2016; Benos, Garratt, and Gurrola-Perez (2017)). Mills et al. (2016) investigate how distributed ledger technology will be applied to payments, clearing, and settlement. The paper identifies the opportunities and challenges facing its practical implementation. Challenges include 1) Business issues i.e., i) benefit of potential use cases, ii) network effects), 2) viable technology solutions. i.e., i) scalability, ii) interoperability, iii)standards development, iv) cryptographic key and access data management, v) information management 3) financial design issues, 4) monetary instruments. i.e.,i financial intermediaries. In addition, it focuses on challenges related to risk management including 1) legal considerations. i.e., i) legal basis of certain DLT components, ii) digital representations of assets, iii) smart contracts, iv) compliance with BSA/AML, v) open 
permissionless systems, vi) Closed permissioned systems, 2) settlement finality, 3) financial risk.

Parlour, Rajan, and Walden (2016) examine the impact of FinTech in the payment system. Two kinds of FinTech innovations are 1) those that affect consumers, 2) those that affect back-office banking operations. They develop a theoretical model in which banks make loans by issuing digital claims to entrepreneurs, who use these claims to pay merchants for inputs in a long-term project. There are two types of liquidity demand before the project ends including 1) merchants cash in claims, 2) the final settlement. They show that a reduction in the requirement for intermediate liquidity induces each bank to increase its lending and improving productive efficiency. However, it can also lead to an increase in the interbank interest rate. Furthermore, innovations that increase interzonal commerce shift investment from more productive to less productive regions, decreasing productive efficiency.

Benos, Garratt, and Gurrola-Perez (2017) argue that 1) distributed ledger technology is likely to reduce costs and increase the efficiency of securities settlement, but final DLT-based solution is very uncertain, 2) authorities should help technological innovation to achieve its potential, 3) DLT-based securities settlement likely to offered by a few providers which could lead to monopoly pricing or price discrimination.

Arvidsson (2018) study on a cashless society in Sweden is informative. He investigates whether Sweden will become a cashless society by looking at key variables such as time to change habits, role of politicians and competition between different payment services. Arvidsson (2018) concludes that Sweden may become a case-free society in five years. However, he points out that elderly, physically and cognitively impaired still depend cash. Hence the role of the state should be to help these groups in the transition process. 
In summary, payments technologies and its regulation is transforming. There is a major gap in research that investigates this change in relation to business models, regulation, consumer attitudes and governance.

\section{Gap four: Reaching vulnerable and excluded customers in both developed and developing countries}

There is much work untouched in this area, in particular, in regards to customer attitudes, included and excluded customers. There are no comparative research studies between countries, regions, jurisdictions and between consumers age or wealth profile. Studies comparing adoption of financial services, FinTech and technology are also lacking. The only studies related in this area is in the applied engineering literature exploring the customer behavioural intentions to use a FinTech service. However, all of these are case studies and focused in developing or South-East countries such as China (Chuang, Liu, and Kao 2016; Leong et al. 2017), Korea (Kim et al. 2016) and Bangladesh (Siddik et al. 2014). Furthermore, these studies focus on successful FinTech adoption. There are no studies that investigate unsuccessful attempts. Insight into what can be learnt from successful and unsuccessful attempts would be particularly useful for policymakers. In addition, there is little consensus among the academic community on the appropriate framework for this type of analysis. Research into different theoretical and analytical frameworks would be a foundation for further work in this area.

As suggested there are applied engineering studies that investigate reasons for customers to use a FinTech service. Chuang, Liu, and Kao (2016) use a Technology Acceptance Model (TAM) in order to understand the consumer behavioural 
intentions in using FinTech Service. They also integrate brand and service trust in there analysis to understand the influence on behavioural intention. They collected 440 effective consumers samples for the analysis. Concepts of TAM include attitude (positive/negative in using technologies, perceived usefulness, perceived ease of use), behavioural intention (willingness to use a technology) and external factors (personal variables of a user etc.) Their results found that: brand and service trust has a significantly positive effect on attitudes toward using FinTech Service. Perceived usefulness has a significantly positive effect on attitudes toward using technologies. Perceived ease of use has a significantly positive effect on attitudes toward using technologies. Attitudes on using have a significantly positive effect on behavioural intention to use the technologies.

Leong et al. (2017) explore the development of a FinTech startup ('007fenqi') in China that offers microloans to college students. The methodology is a qualitative case study. In May 2015, 007fenqi was founded by a group of young entrepreneurs in Zhejiang, China. 007fenqi took into consideration the payment history of a recurrent applicant and whether the applicant has a friend with a good repayment record with the firm. 007fenqi devoted a team to assist the students to access job opportunities. The paper shows that digital technology improved the financial inclusion of previously excluded market segments (i.e. college students with no income).

Kim et al. (2016) investigates the acceptance of payment-type FinTech services in Korean of users by utilizing the Elaboration Likelihood Model and applying variables associated with the Technology Acceptance Model. They find that usefulness, ease of use and credibility had an effect on intention to use, and self-efficacy was found to have a moderating effect on independent and dependent variables. Concern for information privacy was found to be a factor obstructing the path to intention to use. 
Siddik et al. (2014) investigate the factors influencing behavioural intention to adopt (or continue to use) mobile banking in Bangladesh. Based on innovation diffusion theory and decomposed theory of planned behaviour. They added one variable 'perceived financial' to their combined model. Twelve factors were identified. Perceived financial cost is the most significant factor to impact the behavioural intention to adopt. This indicates that mobile phone banking is considered costly to the people which limits adoption.

Gulamhuseinwala, Bull, and Lewis (2015) is a descriptive paper on adoption rates drawn from a 2015 survey of 10,131 digitally active consumers. They look at FinTech adoption in Australia, Canada, Hong Kong, Singapore, the U.K. and U.S. Adoption is high with a weighted average of $15.5 \%$ of digitally active consumers using FinTech products. Hong Kong, where 29.1\% of the digitally active use FinTech products, and Canada, with $8.2 \%$ are the only markets surveyed that differ significantly from the $\mathbf{1 5 . 5 \%}$ average. Projected growth considerable with the adoption rates could potentially double in 12 months. FinTech adoption peaks above $40 \%$ among digitally active users with high incomes.

Gabor and Brooks (2017) is one study that looks at financial inclusion. The paper examines digital-based financial inclusion as a form of organising development interventions through state institutions, philanthropic investment and FinTech companies. It is a discussion paper and not quantitative. They argue that the digital revolution offers the state new ways of expanding the inclusion of 'legible', and global finance new forms of 'profiling' poor households into generators of financial assets.

This section has revealed questions unanswered. There is an opportunity for a focused research agenda tackling these questions. For instance, what is the relationship between customers placing trust in intermediaries impact their desire to share data or engage with unknown new providers? Are security issues a con- 
cern? Furthermore, a considerable gap in the literature is investigating customer benefits and barriers to FinTech adoption. Our discussions have revealed that policymakers are keen on research that identifies and quantitatively investigates the impact of barriers that stop customers using a FinTech service. This research would include quantitative analysis into how to reduce these barriers and how to achieve widespread usage. Furthermore, what type of consumers benefits (age, wealth, education etc.)?

\section{Gap five: Computation, artificial intelligence and large-scale data processing in finance}

We suggest that a major research agenda under this theme is to investigate the implications of using artificial intelligence (AI) in finance. There is no detailed academic study that determines the impact of AI and large-scale processing in finance on any of the following 1) industry structure, 2) consumer perceptions, 3) regulation and 4) governance.

Only a few papers touch on this subject. For instance, Jagtiani, Wall, and Vermilyea (2018) discuss the public policy implications of financial firms using large databases and machine learning (ML). Big data and ML could help financial firms become more efficient in meeting regulatory obligations. However, it can help financial firms to avoid financial regulations. They highlight that financial supervisors are using big data and ML to assist in their monitoring responsibilities (e.g., Office of the Comptroller and the Currency and the Federal Reserve in its Comprehensive Capital Analysis and Review (CCAR) stress-testing process). However, they highlight the two emerging risks 1) use of outside vendors, and 2) cybersecurity risk.

Chakraborty and Joseph (2017) provide an overview of artificial neural net- 
works, tree-based models, support vector machines, recommender systems and different clustering techniques. Concepts including bias-variance trade-off, optimal model complexity, regularisation and cross-validation are discussed. They then provide three case studies 1) Banking supervision-they model the detection of alerts on the balance sheets of financial institutions, 2) Projection of UK CPI in action on a medium-term horizon of two years, 3) investigate funding patterns of technology start-ups with the aim to detect potentially disruptive innovators financial technology. Machine learning models generally outperform traditional modelling approaches in prediction tasks.

Liebergen (2017) discusses applications of machine learning within financial institutions (FI) including credit risk modeling, detection of credit card fraud and money laundering, and surveillance of conduct breaches at FIs. He makes two conclusions regarding machine learning in the industry. First, the ability of machine learning methods to analyze very large amounts of data, while offering a high granularity and depth of predictive analysis, can improve analytical capabilities across risk management and compliance areas in FIs. Second, application of machine learning approaches is highly context-dependent. Hence improved risk management could come at a cost of increased model complexity.

Treleaven (2015) discusses new big data approaches to regulating financial companies. He highlights 1) an open-source platform for FinTech regulation which will support innovation 2) a regulatory XML to help standardize reporting-harmonizing financial regulation across multiple jurisdictions will reduce systemic risk) and 3) an overarching international standards body. He also suggest development of a national financial monitoring system for forecasting systemic risk in the UK. the banking system, financial data research facility, public domain datasets and a secure centralized U.K. data facility. 


\section{Gap six: The relationship between the new financial technologies and financial regulation}

The global financial crisis revealed financial stability risks. There has also be a backlash against the market power of financial service providers. This has led to significant increase in regulation, in compliance costs and inefficiency. FinTech has the potential to improve efficiency of regulation and reduce costs. Philippon (2016b)'s theoretical and empirical economic analysis quantify the inefficiency of the current system. His methodology is taken from Philippon 2015. It involves measurement of financial intermediation through calculation of the income of financial intermediaries, construction of the quantity of intermediated assets and computation of the unit cost of intermediation. He shows that the current system is inefficient with agents willing to pay $8 . \%$ of consumption to bring unit cost of intermediation down to $1 \%$. He qualitatively discusses that the FinTech movement can bring benefits such as cheap and easy funding. Philippon (2016b) argues that bottom-up regulation of entrants will be more beneficial to financial stability and access to services (Philippon 2016a) than a top-down regulation of incumbents.

Our discussions revealed that policymakers are particularly concerned with research in this area. We categorised the existing literature into three areas 1) FinTech and financial stability, 2) Regtech, 3) Policy and the role of government.

\subsection{FinTech and financial stability}

Central bankers and policy makers would like more research in this area. The importance placed on this theme is quite clear from papers by central bankers. For instance, Financial Stability Board (2017) developed a framework that defines FinTech activities and the potential benefits and risks to financial stability. The paper highlights that although FinTech activities are small compared to a 
financial system, bodies should account for FinTech in risk assessment. The paper identifies the following 10 priority issues that require authorities attention 1) managing operational risks from third-party service providers, 2) mitigating cyber risk, 3) monitoring macrofinancial risks, 4) cross-border legal issues and regulatory arrangements, 5) governance and disclosure frameworks for big data analytic, 6) assessing the regulatory perimeter and updating it on a timely basis, 7) shared learning with a diverse set of private sector parties, 8) further developing open lines of communication across relevant authorities, 9) building staff capacity in new areas of required expertise, 10) studying alternative configurations of digital currencies. This would reduce the barriers to the benefits of innovation and the promote financial stability. In addition, the paper emphasis benefits to greater international cooperation to mitigate divergence in the regulatory framework. 1,2, and 3 are the priority areas for international cooperation. The report suggests that the lack of data is a constraint on assessing the implications of FinTech on financial stability.

Villeroy de Galhau 2016 points out to reconcile innovation and stability, Banque de France and the French prudential supervisory and resolution authority must adhere to two principles. Firstly, absolute guarantee of security of transactions and payments and secondly, an adaptation of regulations to address the development of FinTechs.

There is relevant work undertaken by academics. Minto, Voelkerling, and Wulff (2017) develop a theoretical framework to understand the risks to financial stability of FinTech and the appropriate policy responses. The paper introduces four filters to organise FinTech including 1) economic function, 2) disruptive potential, 3) disintermediation, 4) decentralization. Each stage of filtering process will develop understanding the potential risks to financial stability of the FinTech product/area. In addition, it may impact the design regulatory policy. In the first 
stage, FinTech is placed into one of four economic functions, 1) payment services, 2) lending and capital raising, 3) investment and trade, 4) clearing and settlement. Second stage split into sustaining and disruptive innovations. Third filter looks at whether FinTech is capable of breaking up traditional networks. The paper shows the working of the filter process with the case study of ICO. Lai and Van Order (2017) use a banking network model based on Acemoglu, Ozdaglar, and TahbazSalehi (2015) to investigate the impact of FinTech on financial fragility and contagion. In the network model variables include interbank obligations, wages and operating expenses and other senior liabilities. They extend the banking network model by linking it to FinTech finance when the latter becomes a form of shadow banking. The paper then formulates a general model of Fintech-bank partnership shadow banking. They show how the network reacts to increases in FinTech firms and banks in the FinTech-bank partnership. They provide examples with China. However, note that the paper does not use data.

Interestingly, FirstRand Bank (2016) argues that central banks should implement issue a cryptocurrency as it will 1) augment their ability to understand economies, 2) reduce systemic risks, 3) facilitate effective transmission of monetary policy.

Although not specific to FinTech, Danielsson (2017)'s paper is relevant. Danielsson (2017) points out that as technicalities and objectives are defined, risk management and micro-prudential supervision are suited for AI. Nonetheless, AI could destabilise the financial system and increase systemic risk.

Danielsson, Macrae, and Uthemann (2017) provide more discussion of how AI can increase systematic risks. The paper suggests that AI is useful for controlling system with wide data and clearly understood risks. As local optimisation leads to a solution to a global problem, there is no need to control the risk of the entire financial system. However, macroprudential regulations are focused on systematic 
risks and controlling risks of banks separately may increase dangerous risks which occur at the intersection between various parts of the system.

Schindler (2017) touches on the subject, but does not go into detailed analysis. He discusses two main points. First, the paper highlights why FinTech is occurring now. He uses a supply and demand framework to explain this. On the supply side there are technology, regulation, spirals of innovation, macroeconomic/financial landscape changes. Demand factors include demographics. His second main point is that FinTech innovations are deep, have a great potential to transform and cause financial instability. The paper points out that many of FinTech's innovations are genuine and foundational which has the ability to transform the industry. The paper does not go into depth why it will cause financial instability. His argument lies on a link between the greater depth of innovation and a greater chance of financial instability.

\subsection{Policy and the role of government}

The range of topics discussed in the literature is wide with no coherent research agenda. With no empirical or quantitative analysis, there is an opportunity to address this gap.

Several paper argue for regulation to move beyond providing strict rules to regulators working with the financial service providers. Tsai and Kuan-Jung (2017) determine the viable adaptive regulatory regime for online supply chain financing. He argues that principles-based strategy should be adopted not strict rules. This would balance financial stability and access to FinTech. Hallberg and Olsson (2018) argue that the regulatory body should work with innovators and encourage R\&D. They suggest following the successful sandbox model which was implemented successfully in the UK. (Jonsdottir et al. 2017). Furthermore, they emphasis programming skills to be taught at a young age and enhanced up to the 
master's level. Freji 2018 focuses on Sweden with case studies. He offers a regulatory innovation framework that can be used by the government to understand the impact of new regulations on entrepreneurs. The innovation framework is developed through combining four areas of regulation change which impact the firm and four opportunities that arise. The four areas of regulation change are product design, service processes, customer relationships, and technology platforms. The four opportunities that come out of these regulatory changes are dominant designs, firm collaboration, technical requirements, and legal protection. He then identifies six innovation strategies for dealing with any given regulatory change and corresponding opportunities.

Several papers argue that FinTech may make it harder for regulators to appropriately regulate including Brummer and Yadav (2017) and Van Loo (2017). Brummer and Yadav (2017) develop a framework that shows that regulation of financial innovation is bounded by a policy trilemma ('Trilemma'). Regulators at best can only obtain two of the following 1) simplicity in rules, 2) maintain market integrity and stability, and 3) encourage financial innovation. They discuss the major eras of financial regulation illustrating the Trilemma challenge. They highlight tradeoffs and the regulatory implications throughout history. For instance, in the 20s, the emphasis was on the free market and financial innovation. The simplicity of rules was critical. Financial stability was an issue due to lack rules. This led to the Great Depression. New Deal would lead to the emphasis on market integrity. The Dodd-Frank Act demonstrates that market integrity was the priority. The paper suggests FinTech exacerbates the Trilemma due to the following 1) complex algorithmic programs to automate financial services through, 2) the provision of financial services often by smaller enterprises, and 3) reliance on big-data to design of FinTech products. Van Loo (2017) highlights how FinTech is changing the structure of competition and suggest that financial agencies are incapable to 
respond. He highlights four ways regulators have failed to adapt including 1) to a new competitive environment, 2) to FinTech providing a partial market-driven response to the problem of 'Too Big To Fail', 3) to FinTech potential to accelerate monopoly power, 4) in competition policy that is reducing welfare in the US.

There has been some relevant work on standardisation including Milne and Chisholm (2013); Milne and Parboteeah (2015); Houstoun, Milne, and Parboteeah (2015). Milne and Chisholm (2013) study a common financial language from conceptual and practical perspectives. CFL for data management can lead to considerable efficiency and risk-management benefits. CFL is likely to evolve and gradually adopted. The paper discusses the following case studies 1) FIX protocol, 2) ISO 20022, 3) global LEI system. Lessons learnt include benefits of the common language of standardisation and unambiguous referencing. Milne and Parboteeah (2015) discuss the outcome of a 'Delphi' survey of professionals, focussing on the business and economic benefits of standardization in global financial markets and the barriers to standardization. 70 members of the working group were invited to complete the survey, with 15 members completing the whole survey, Delphi survey was conducted in two rounds. The first round was open from 29th Aug 2014 until 17th Nov 2104. The second round was kept open from 14th January 2015 until 16th February 2015. The first main conclusion is that specialists in standards expect significant benefits from standardisation in financial markets which are yet to be realised. The second main conclusion is that regulators need to heavily promote standardisation and reduce barriers. Houstoun, Milne, and Parboteeah (2015) examine the market failures that can hinder standardisation and recommends actions to overcome them. Market failures include 1) challenge of agreeing and adoption of a standard, 2) commercial interests resisting standardisation. In addition, standards-setting institutions in financial markets are undeveloped and standards-setting is underdeveloped for recording of financial 
exposures within individual firms. The paper suggests the following actions to improve standardisation in global financial markets 1) promotion of dialogue from researchers and practitioners, on identifying specific opportunities for employing standardisation to promote business efficiency and improve market transparency, 2) engagement of senior management to support standardisation and standards institutions.

Other studies are loosely connected to the above work. Østbye (2018) studies how regulation may obstruct the core of cryptocurrencies' protocols. Regulation might affect the mechanics of validation, pseudo-anonymity design, and the structure of rewarding validation. Regulation encourage protocols for compliance and protocols circumventing regulation.

Holden and Malani (2017) examine whether blockchain can rectify the contract holdup problem. They point out that renegotiation design and revelation mechanisms solutions have so far been practically not viable. This is due to the strong commitment rules than the court system cannot provide. On the other hand, blockchain can force contracts to be unable to renegotiate or force commitment.

Odinet (2018) explores numerous areas in the FinTech market. This law paper provides an overview of products FinTech firms offer and the part played by machine learning in assessing a borrowers creditworthiness. The main analysis of paper is on the consumer complaints, current government responses, consumer protection and landscape and recommendations for future regulation of bitcredit. He uses a multi-year set of complaints submitted to CFPB in regards to products offered by FinTech firms. The paper provides examples of complaints found in the dataset that emphasis certain problems. These include loan processing problems, changes in the terms of loans-(i.e., interest rates, fees, penalties), changes in access to lines of credit etc. Policy recommendations include accessing industry information, protecting against lending discrimination, interfacing with the technology, 
use and sale of consumer data and designing a regulator.

Reyes (2016) develops a law based endogenous theory of decentralised technology regulation. The proposal involves regulators to enact a law via statute and them implement that statute through code. The code would be formed by a cooperative process with the technologies core developers and consensus from the network. This would imply that regulation is endogenously incorporated into the decentralized ledger technology with applications running on top of the technology.

Chan and Milne (2013) examine the global legal entity identifier (LEI) system for the identification of participants in financial markets. Interviews with data professionals reveal the following potential benefits from the global LEI system 1) efficiency gains in processes undertaken by financial institutions dealing with corporate and wholesale customers, 2) better measurement, monitoring and response to risk exposure. Monitoring systemic risk is possible if there is an accepted universal standard for identification in all business processes. To make this a reality requires 1) roadmap and timetable, setting out how the global LEI will move forward, 2) Discussion and agreements between regulators and industry on the use of LEI in all business areas, 3) guidance of LEI use in KYC/AML, 4) guidance of use of LEI in regulation.

Karkkainen et al. (2017) argue that we must update the school curriculum to address the new set of skills in financial services resulting from the development in FinTech. They suggest skills gaps are mainly technical. There needs to be a synthesis of the finance and ICT educational curriculum, bringing the two strands together in a cohesive manner. Options could be conversion graduate programmes emphasizing either of the two subjects. At the undergraduate level, the interdisciplinary collaboration between finance and ICT programmes would be worthwhile.

Hendry and Zhu (2017) develop a framework to investigate the adoption of E-money and monetary policies in the presence of both E-money and central bank 
fiat money. The paper explores the following questions, 1) should central banks hinder E-money adoption? 2) if so, how should their do that? 3) if no, how should the central banks adjust their monetary policies? 4) should central banks issue their own e-money? They show that e-money is adopted only if the proportion of transactions in which e-money has an advantage is big. They also show that emoney can lead to a monetary policy coordination concern (i.e., the Friedman rule is not optimal for fiat money issuer if e-money issuer runs a sub-optimal monetary policy).

Chellappa and Pavlou (2002) highlight antecedents of consumer perceptions of security. They argue that on the Internet customer perceptions of information security is influenced by the mechanisms of encryption, protection, verification, and authentication. They undertake an empirical regression analysis to evaluate the interrelationships related to perceived security. Consumer perceptions of how their information is stored and how their information was handled during transit are important elements of perceived security.

Lootsma (2017) is an opinion piece and suggest that KYC distribution over blockchain are considerable. The piece points to IDIN in the Netherlands as a successful application of digital identity outside of the financial institutions. He suggests that for banks to gain in efficiency, it is optimal to align implementation of blockchain with new RegTech and FinTech innovations.

Gelb (2016) suggests that as a primary policy objective is a financial inclusion, know-your-customer (KYC) requirements become important to strengthen financial integrity. He recommends greater attention to national identification systems as these are the basis for Customer Identification and Verification (CIV). This will accelerate the use of digital technology to move from cash-cash wire transfers to account transactions.

Weber (2017) points out that 'know-your-data' (KYD) may add to the prin- 
ciple of 'know-your-customer' (KYC). More data-driven regulations models. He argues data needs to be gathered globally on a real-time basis.

Li and Mann (2018) offer a model that they suggest can provide guidance to regulators to what ICOs to ban and when to allow them to proceed. In their model the use of an ICO for launching platforms, ICO can increase platform value, make the launch of a valuable platform more likely, and increase social welfare. The two mechanisms that it acts to increase value are 1) ICO can solve a coordination failure in platforms with network effects, 2) it can harness the 'wisdom of the crowd' by aggregating dispersed information about platform quality.

The range of topics unaddressed is enormous. For instance, was is the role of regulatory bodies in encouraging technological innovation in financial services? Is there a governance problem of incumbents that stops innovation? Is there are potential for technological innovation to improve governance?

\subsection{Regtech}

Compliance costs are approaching 10\% of financial firms' cost base (Duff\&Phelps 2018). It is no surprise that there is much opportunism about Regtech potential to automate regulation and reduce compliance costs.

Although there is literature on Regtech, it is almost exclusively based in law including Arner, Barberis, and Buckley (2015); Arner, Barberis, and Buckley (2016b) Arner, Barberis, and Buckley (2016a); Baxter (2016); Enriques (2017) Micheler and Whaley (2018) and Packin (2018)). There is an opportunity for an interdisciplinary approach with law or other disciplines to analyse the implications of RegTech.

Arner, Barberis, and Buckley (2015) investigate the evolution of FinTech. They highlight two approaches to regulation, UK and China. The UK is moving away from a product-based to a principle-based approach, focusing on prudential regu- 
lation and consumer protection. China has maintained product-based principles with small/medium transactions handled by internet finance companies. Larger transactions remain with state-owned institutional players. In both cases there needs to be more forward-looking approach by regulators. They suggest a common international approach to FinTech regulation. Arner, Barberis, and Buckley (2016b) point out that as RegTech will continue to evolve it will transform the future of financial regulation. Arner, Barberis, and Buckley (2016a) argue that RegTech so far has been focused on the digitization of manual reporting and compliance processes, which has led to cost savings for the regulators and to the industry. However, the potential is much greater including addressing risks. The authors propose a sequenced set of reforms. They highlight the UK FCA's Project Innovate as a good pilot. However, they suggest that it become a system-wide framework with the principles behind regulatory sandboxes being enhanced by introducing the concepts of Minimum Regulatory Obligations. Furthermore, Recovery and Resolution Plans should be adapted to fit start-ups.

Baxter (2016) argues that regulators face an increasingly complex task in supervising modern financial institutions. He suggests preserving regulatory discretion rather than through formal congressional direction. RegTech solutions will help reduce regulators burden with automation of mechanistic analyses and allow regulators to exercise discretion and concentrate on making important regulatory judgements.

Enriques (2017) highlights four uses of RegTech technology including 1) Operations RegTech, 2) ComplianceTech, 3) OversightTech, and 4) PolicymakingTech. He then describes four roles of regulators in regards to RegTech. They can act as 1) developers/users of RegTech products, 2) buyers/users of RegTech products, 3) coordinators of the development of the market, or 4) supervisors of RegTech firms. Finally he discusses four challenges that regulators face in relation to FinTech and 
RegTech which are 1) human resources, 2) internal governance, 3) cybersecurity risk, and 4) related to their goals (i.e. preventing, catching and punishing misbehaviour). He concludes that RegTech is very likely to improve supervision quality. However, regulators need to have in place IT literate individuals to help the transition process.

Micheler and Whaley (2018) highlight that regulators' actions need to judge by the five criteria of 1) democratic legitimacy, 2) accountability, 3) fair, accessible and open procedure, 4) expertise, and 5) efficiency. The paper evaluates disadvantages and advantages of following approaches 1) command-regulation, 2) meta-regulation, co-regulation, 3) enforced self-regulation, and 4) self-regulation. The paper concludes that capture could be a big problem. Furthermore, the paper warns that there is no reason to assume that regulatory technology will align interests of regulated entities with the interest of regulatory standards. Technology will reflect the interest of those that programmed it.

Packin (2018) assumes that RegTech will improve regulation. However, the paper argues that not all corporate governance problems can be solved with RegTech. Barriers exist which make RegTech difficult to be adopted in some areas. RegTech cannot solve corporate culture ethical issues. Third it may reduce good judgement with unclear programmed logical. Fourth, there could be cyber risk. Hence, careful design is vital.

There are only handful of papers in other disciplines. Treleaven and Batrinca (2017) is a discussion written by computer scientists. The paper examines the RegTech areas that are viable for automation using blockchain technology. The areas are intelligent regulatory advisor, automated monitoring, automated reporting, regulatory policy modeling and automated regulation. They provide examples for each e.g. agent-based computational models to evaluate laws prior to deploymentregulatory policy modeling. The paper concludes that blockchain smart contract 
technology will disrupt effect legal services more than the impact FinTech is having on financial services.

Note that Bank for International Settlements (2018) points out the following risks to the consumer sector of the emergence of FinTech 1) data privacy, 2) data security, 3) discontinuity of banking services, 4) inappropriate marketing practices. Opportunities include 1) financial inclusion, 2) better and more tailored banking services, 3) low transaction costs. Risks to banks and banking system are numerous including cyber-risk, operational risk, compliance risk etc., Opportunities include improved and more efficient banking processes etc.,

\section{Identity, security, data privacy and their reg- ulation in financial services}

There are almost no studies that investigates biometric identification and cyber security in relation to the financial service industry. There is a serious gap in studying government policy in establishing identity, effective enforcement of 'know your customer/ client' and 'anti-money laundering' regulation. A key area that could be investigated is the relationship between data security and consumer attitudes in using a FinTech service.

We found one paper that only circumvents the subject of identity. Lewan (2018) does not investigate digital identity. However, through interviews with business leaders and regulators in Sweden, some relevant points are raised. For instance, Schuil (CEO and co-founder of the Bitcoin-focused startup Safello) suggests identity will be crucial in giving power to the customer. Schuil argues that it enables a global ID and empowers the customer...to independently move around the world-which could then become a borderless world. Ulf Ahrner (CEO at Primepilot) points out that before you could not identify people remotely. He suggests 
now $90 \%$ have BankID and you can identify most Nordics without meeting them. 


\section{Cryptofinance radical technology-based al- ternatives to conventional regulated financial services}

We include this section not to provide a research agenda, however, for completeness and to offer an overview of the existing literature. Unlike the gaps, cryptofinance has been extensively investigated. This section is categorised into disciplines that study crypofinance. By this way of categorisation, it is easy to see how the disciplines study cryptofinance. These categories include 1) Cryptocurrencies: Economics, 2) Cryptocurrencies: Computer Science, 3) Cryptocurrencies: Payments, 4) Cryptocurrencies: Finance 5) Cryptocurrencies: Technology/innovation, 6) Cryptocurrencies and cryptoassets: Law and regulation, 7) Blockchain: Economics, 8) Blockchain: Law, 9) Blockchain: Other.

\subsection{Cryptocurrencies: Economics}

Pieters (2016) shows empirically that price data of the internationally traded cryptocurrency Bitcoin when adjusted for market specific elements can approximate unofficial exchange rates. She uses data from the aggregation website Bitcoin Charts on daily transaction-weighted bitcoin prices. This is adjusted for market specific elements. This can then be used to highlight the magnitude of the distortion caused by capital controls and exchange rate manipulations.

Pieters (2017) is a discussion paper based on her previous research and data. However, it makes argues that if cryptocurrencies continues to grow, cryptocurrency flows size relative to international financial markets will increase. Consequently, central banks when making monetary policy has to consider that consumers can switch to an unregulated alternative currency. 
Pieters and Vivanco (2017) determine that systematic differences in bitcoin prices across 11 different markets representing 26\% of global bitcoin trade volume. They argue that this results from characteristics of markets. Their analysis shows that markets that do not require customer identification for establishing an account are more likely to deviate from representative market prices than those which do. They argue that this means that financial regulations including knowyour-customer regulations can have a non-negligible impact on the bitcoin market.

Bolt and Oordt (2016) develop an economic framework to investigate the exchange rate of a virtual currency. Their model shows that the exchange rate will become less sensitive to the impact of speculative behaviour with more widespread use of the virtual currency.

Gandal and Halaburda (2016) study how network impact competition in the nascent cryptocurrency market. Data is used for the analysis. Bitcoin is the leader in the market. In the early stages there was no evidence of a winner-take-all effect. However, in the later stages of the market, Bitcoin has appreciated against the USD, while other currencies depreciated against the USD. The data shows strong network effects and winner-take-all effect.

Harvey (2016) discusses how crypto finance works with applications such as Bitcoin, debit cards and the miners.

Hendrickson, Hogan, and Luther (2016) investigate whether government would be successful at banning Bitcoin. They endogenize the matching process. The paper shows that banning will be difficult if some agents strictly prefer bitcoin. These agents can prevent others using the official currency resulting from the matching process.

Hileman (2015) offers a Bitcoin Market Potential Index to rank 178 countries in terms of the greatest potential of Bitcoin adoption. The index has 40 variables related to Bitcoin's functions of store of value, medium of exchange, and tech- 
nology platform. Argentina and Sub-Saharan Africa are the country and region, respectively, where Bitcoin has the greatest potential for adoption.

Bouoiyour and Selmi (2017) investigate the factors which increase Bitcoin's value. The factors include 1) fundamental, macroeconomic and financial determinants, 2) the speculative factors, 3) the technical drivers, 4) events occurring in 2016. The analyse relationships starting from 01 January 2015 to 30 December 2016 (729 observations). They use Bayesian quantile regressions to determine the structure of dependence of Bitcoin's price and its determinants across the entire conditional distribution of Bitcoin's price movements. The most important determinant of Bitcoin's price rise when market was improving are 1) use of Bitcoin in trade, 2) uncertainty around China's deepening slowdown, 3) Brexit and India's demonetization. When the market was normal, Donald Trump being the president of United States was important in increasing the price. When market was declining the Venezuelan currency demonetization and gold's price were important determinants.

Chiu and Koeppl (2017) analyse the optimal design of cryptocurrencies and assess quantitatively the viability of these currencies to support bilateral trade. The paper models blockchain, mining and double-spending incentives within an economic model. The main features of their cryptocurrency model are 1) a consensus protocol, 2) settlement lags, 3) a reward scheme. They undertake a numerical analysis of Bitcoin. Problem with cryptocurrency is double-spending. The paper estimates Bitcoin leads to a welfare loss of $1.4 \%$ of consumption which can be reduced to $0.08 \%$ with an optimal design. Optimal design would reduce mining and finance mining rewards with money growth but transaction fees.

Dwyer (2015): Digital currencies (Bitcoin) use P2P networks and open-source software to stop double spending and create finality of transactions. The paper studies how these technologies and a limit on quantity can lead to an equilib- 
rium in which a digital currency has a positive value. He points out that the value of Bitcoin is determined by the demand for Bitcoin's in conjunction with the rules governing supply. He argues that foreign currency exchanges can lead to widespread use of digital currency. Furthermore Bitcoin may reduce governments' ability to generate revenue from inflation.

Gandal et al. (2018) examine the implication of suspicious trading on the Mt. Gox Bitcoin currency exchange. 600,000 Bitcoins (BTC) valued at \$188 million were fraudulently obtained. Dependent variables are the daily difference in the exchange rate of BTC. Independent variables include dummy variables for Markus, Willy (suspicious traders are Markus Bot and Willy) and other attacks. USD-BTC exchange rose by $4 \%$ on days when suspicious trades by the two agents took place. Slight decline on days without suspicious activity.

Prat and Benjamin (n.d.) develop a continuous time model which utilises the BTC-USD exchange rate to forecast the computing power of the Bitcoin network. In the model demand of bitcoin is given and the trend of the exchange rate is used to predict the hashpower of the network. They calibrate the model for two time periods as follows 1) $01 / 04 / 2011$ to $31 / 01 / 2013,2$ ) $01 / 10 / 2014$ to $31 / 03 / 2017$. The paper highlights that the accuracy of the model is proven with out-of-sample tests entry rule investigations.

Hileman and Rauchs (2017) discuss their cryptocurrency benchmarking study. They collected non-public data from over 100 cryptocurrency companies and organisations across 38 countries and five regions. Exchanges, wallets, payments and mining are discussed. Key points include 1) 1,876 people are working fulltime in the cryptocurrency industry, 2) $52 \%$ of small exchanges hold a formal government license vs. 35\% of large exchanges, 3) Between 5.8 million and 11.5 million wallets are estimated as active, 4) $79 \%$ of payment companies have existing relationships with banking institutions and payment networks, 5) considerable concentration of 
mining in some Chinese provinces.

Rauchs (2016) examines the Bitcoin business ecosystem and factors that are behind the change. He applies a longitudinal dataset of 514 companies and projects.

Cheah and Fry (2015) apply an econometric analysis of Bitcoin. The data consists of daily closing prices for the Bitcoin Coindesk Index from July 18th 2010 to July 17th 2014. The paper finds Bitcoin exhibits speculative bubbles. The fundamental price of Bitcoin is shown to be zero.

Huberman, Leshno, and Moallemi (2017) uses an economic model to explore three main themes of the Bitcoin system including 1) the raising of revenue to pay for the infrastructure, 2) usage fees, 3) the implications of changing parameters in the protocol. They show that the system requires congestion to raise revenue and fund infrastructure. Users who wish to gain processing priority over other users and avoid delays pay transaction fees. Miners, who compete and provide their services at cost, provide the system's infrastructure. The system removes the dead-weight loss from monopoly. However, it adds other inefficiencies.

\subsection{Cryptocurrencies: Computer science}

Eyal and Sirer (2014) show that Bitcoin mining protocol is not incentive-compatible and not secure against colluding miners. The conventional belief is that the protocol rewards miners strictly in proportion to the ratio of their overall mining power. However, the paper shows that this is not the case. There is an incentive for selfish mining with the pool keeping its discovered blocks private with mining on its private branch. Honest nodes mine on the public chain. The selfish miners reveal blocks from their private chain to the public, when the length of the public branch is near that of the private. Honest miners waste proportionally more resources than selfish miners. Hence, rational miners would join the selfish mining pool. The paper proposes a modification to the Bitcoin protocol that protects Bitcoin. 
Selfish mining by pools that command less than $1 / 4$ of the resources is forbidden.

Kogias et al. (2016) point out literature has now shown that Bitcoin is vulnerable to transaction reversibility, double-spending, and strategic mining attacks. The problem essentially rests in the fact that the algorithm for Bitcoins consensus provides only probabilistic consistency guarantees. The paper introduces a 'ByzCoin', a cryptocurrency like Bitcoin enhanced with strong consistency. Principles are based on the Practical Byzantine Fault Tolerance (PBFT) algorithm. ByzCoin tackles the four key problems in using PBFT's strong consistency to cryptocurrencies. These include 1) open membership, 2) scalability to hundreds of replicas, 3) proof-of-work block conflicts, and 4) transaction commitment rate.

Heilman et al. (2015) present and quantify the required resources for eclipse attacks on the peer-to-peer bitcoin's on nodes with public IPs running Bitcoin version 0.9.3. They develop mathematical models of the attack including validation by Monte Carlo simulations, measurements and experiments.

Gervais et al. (2015) show that current scalability measures adopted by Bitcoin is not compatible with the security of the system. They highlight the four Bitcoin's measures that are incompatible as 1) internal reputation management system to tackle the broadcasting of ill-formed blocks, 2) the information spread in the network is minimized by an advertisement-based request management system, 3) static timeouts attempts to prevent blocking allowing for network outages, congestion, and slow connections, and 4) order of the received transaction advertisements is kept by clients so that if a request is not delivered the next peer in the list is queried. The paper shows how an adversary can exploit these scalability measures in order to 1) delay and 2) extend the block delivery time of message advertisements. The paper investigates counter-measures to enhance Bitcoin security without deteriorating its scalability.

Nayak et al. (2016) augment the mining strategy to include novel 'stubborn' 
strategies. For a wide parameter range the miner earns more revenue. The selfish mining attack is not (in general) optimal. By composing mining attacks with network-level eclipse attacks a miner can increase gain. They show that in some outcomes, victims of an eclipse attack can benefit from being eclipsed.

Zhang, Daian, and Kaptchuk (2018) develop techniques that solve an impasse problem by making cryptographic access structures dynamic. They point out that conventional $(\mathrm{M}, \mathrm{N})$-threshold signature schemes, users have to make a problematic choice. The choices, through loss of a single key renders the signing capability unavailable, creating paralysis in systems that use signatures for access control. They call their technique to solve the problem as 'Paralysis Proofs'. They apply the tool to recover from cryptocurrency key loss such as player disappearance.

Borge et al. (2017) highlight that permissionless blockchain-based cryptocurrencies use proof of work $(\mathrm{PoW})$ or proof of stake $(\mathrm{PoS})$ to ensure their security. They originate a proof of personhood (PoP) instead. This binds physical entities to virtual identities to ensure accountability and preserve anonymity. They then introduce PoPCoin, a cryptocurrency with a consensus mechanism. They argue this leads to fair wealth creation and hence could lead to the foundation for basic income.

Bentov et al. (2017) propose 'Tesseract', a secure real-time cryptocurrency exchange service. They highlight that centralized exchange can susceptible to fund theft. In addition, decentralized exchanges cannot provide real-time cross-chain trades. Tesseract overcomes these problems by using Intel SGX.

Miller and Bentov (2017) propose cryptocurrency-based lottery protocols that do not require collateral from the players. The protocols are based on tournament bracket construction. Their lottery protocols allow players with little money to be involved. Furthermore, the Ethereum-based implementation of the lottery is very efficient. 
Schilling and Uhlig (2018) investigate the evolution of Bitcoin prices and the consequence on monetary policy using an endowment economy model. The model has 1) two types of infinitely-lived agents, 2) two types of money, Bitcoin and Dollars 3) a central bank that keep the real value of Dollars constant with monetary injections, 4) Bitcoin production decentralised. They suggest that a version of Kareken and Wallace (1981)'s condition is obtained. They show that Bitcoin prices form convergent supermartingales/submartingalas under some conditions with corresponding implications on monetary policy.

\subsection{Cryptocurrencies: Payments}

Garratt and Wallace (2018) point out that the value of Bitcoin is that it rests on self-fulfilling beliefs. In their model they assume there is a fixed stock of Bitcoin that is valuable today only as it is believed others will treat it as valuable in the future. The paper highlights the difficulties in determining money prices in the one-money model and two-money world (add outside (fiat) money). The paper shows various equilibria that provide no real value for Bitcoin. They note that there is an infinite number of equilibria, hence its impossible to describe them all. They point out that the problem of determining Bitcoin's value is due to the ease of creating perfect substitutes.

Garratt (2016) is a discussion paper on 'Project Jasper', which was misinterpreted as a Canadian version of Fedcoin. The distinction between CAD-coin (digital money in Project Jasper) and Fedcoin is that Fedcoin is intended as a substitute for cash. For CAD-coin privacy at conversion is not required. Fedcoin would be issued onto a public ledger by the central bank and would be convertible one-one for USD. CAD-coin represents deposit receipts backed money of the central bank.

Kahn, Rivadeneyra, and Wong (2018) investigate whether a central bank should 
issue a universally accessible electronic liability (e-money). Essentially, the paper looks at whether new technology has changed the tradeoffs between centralized and decentralized payments systems. Tradeoffs depend on 1) technological setup, 2) improvement in the transmission of monetary policy, 3) risks to privacy from cyber attacks, 4) financial stability impact. They look at various proposals. The main finding is that DLT and mobile computing have not significantly changed the tradeoffs of providing central bank accounts to the public. They emphasis unanswered questions such what is the quantitative impact token-based system offered by the central bank to bank deposits and bank lending?

Henry, Huynh, and Nicholls (2017) propose a method to collect a national sample to track the ubiquity and usage of Bitcoin in Canada using the Bitcoin Omnibus Survey (BTCOS). BTCOS was conducted as an online omnibus survey by Ipsos. There were five questions on the survey. For instance, the first question was asked to gauge awareness: 'Have you heard of Bitcoin?' They find that 64 \%of Canadians have heard of Bitcoin, but only $2.9 \%$ own it. Bitcoin awareness is strongly associated with men and those with college or university education. Bitcoin awareness is more concentrated among unemployed individuals. Bitcoin ownership is associated with younger age groups and high school education.

Milne (2017) investigates the potential improvement on monetary arrangements using the time-ordered immutable transaction records (i.e., blockchains, mutual distributed ledgers) to record cryptocurrency transactions. The paper argues that by putting money (government fiat money and bank money) off-balance sheet a distributed ledger can ensure the integrity of money and payments arrangements in the event of bank failure. This would mean central bank reserves would not be required for bank payments settlements and consequently no requirement for 'too big too fail' protection of banks. 


\subsection{Cryptocurrencies: Finance}

Yermack (2015) highlights that Bitcoin fails to satisfy the criteria of a 'bona fide' exchange rate which are 1) medium of exchange, 2) a store of value, and 3) a unit of account. He concludes with obstacles including decimal pricing of common household goods and the few merchants who accept it. The paper also points out that Bitcoin behaves like a speculative currency with the excessive volatility.

Yermack (2017) investigates the implications of the use of blockchains on corporate governance from the perspective of corporate managers, institutional investors, debt investors etc. Greater visibility implies Institutional investors will find it harder to disguise their trades despite from benefiting from low trading costs. In addition, managers with stock-based compensation will lose profit from legal insider trading. Voting from shareholders will become more reliable. Companies using real-time accounting will reduce the role of auditing and less need for litigation.

Figà-Talamanca and Patacca (2018) study the relative impact of measures on mean or on the variance of Bitcoin returns. The paper measure market attention by filters on time series for the trading volume or the SVI Google searches index. They fit non-linear econometric models to data from January 1, 2012, to October 31, 2017. They find strong evidence for the trading volume measures to affect both the mean of Bitcoin returns and volatility. They conclude that Bitcoin returns are driven by market attention.

Foley, Karlsen, and Putniņš (2018) find that 25\% of Bitcoin users and 51\% of Bitcoin transactions are associated with illegal activity. Cryptocurrencies have enabled 'black e-commerce'. For the most recent sample of April 2017, 24 million Bitcoin users that use Bitcoin used it primarily for illegal activities. They argue that the techniques developed can be applied for cryptocurrency surveillance (i.e., monitoring trends in illegal activity). They use two methods to provide estimates 
of the illegal activity, 1) Network cluster analysis, 2) Detection controlled estimation (DCE).

Bianchi (2017) utilises a new data set of prices, volumes traded, and market capitalization for a number of cryptocurrencies to empirically investigate the relationship between asset classes (e.g., equity, bond, etc., ). He finds a small relationship between cryptocurrencies and commodities. However, there are no volatility spillover effects. He uses a panel Granger causality test and a panel Vector Autoregressive (VAR) model to demonstrate that macroeconomic influences do not drive cryptocurrency markets trading activity.

Malinova and Park (2017) suggest that Blockchain in financial markets provide investors new avenues to manage transparency of their holdings. Their theoretical model considers two main characteristics of a distributed ledger, the mapping between identifiers and end-investors and degree of transparency of the ledger. They study how the design of these characteristics impact investor welfare in a theoretical model of intermediated and $\mathrm{P} 2 \mathrm{P}$ trading. Welfare is highest in the most transparent environment. Without full transparency, welfare is weakly higher if investors split holdings among many identifiers.

Mai et al. (2018) study whether Twitter sentiments (the vocal minority, silent majority) impact the value of bitcoin. They use machine-based methods and explanatory econometric analysis. They use a Python-based Web crawler to collect discussion content from Bitcointalk.org between January 1, 2012, and December 31, 2014, to obtain social media metrics. They also used traditional Internet activity measures and control variables from the financial market. The impact on bitcoin by social media are driven primarily by the silent majority ( $95 \%$ of users who are less active with contributions of $40 \%$ of the total message). They also find extended blog posts are more influential than brief tweets. 


\subsection{Cryptocurrencies: Technology/Innovation}

Athey, Catalini, and Tucker (2017) investigate distortions in consumer behaviour which could hinder consumers' ability to protect their privacy. A variety of distortions in the notice and choice process are investigated. They use data from a digital currency experiment at the Massachusetts Institute of Technology where every undergraduate student was offered $\$ 100$ in Bitcoin in the fall of 2014 . The three main findings are 1) incentives explain the privacy paradox-people say they care about privacy, but willing to provide private data when incentivized, 2) small navigation costs frictions around privacy choices can heavily impact technology selected, 2) information on encryption reduced privacy-enhancing behaviour.

Catalini and Gans (2018) investigate how entrepreneurs can use initial coin offerings to fund venture start-up costs. The model is theoretical a standard in the entrepreneurial finance literature. An entrepreneur faces an upfront cost, three time periods, agents have a discount factor, quality of products is determined. The paper shows that entrepreneurs can use 1) ICO to induce buyer competition for the token which reveals consumer value, 2) venture returns are independent of committed growth in the supply of tokens over time, 3) revealing consumer demand information, crypto tokens may increase entrepreneurial returns beyond what can be achieved through traditional equity financing, 4) crypto tokens can encourage stakeholder coordination when networks effects are present.

\subsection{Cryptocurrencies and cryptoassets: Law and regula- tion}

Golumbia (2016) is a book with 6 chapters 1) bitcoin, digital culture and right-wing politics, 2) central banking, inflation, and right-wing extremism, 3) an overview of bitcoin, 4) central banking conspiracy theories, 5) software as a political program, 
6) the future of bitcoin and the blockchain. The book argues that right-wing extremist concepts have harmed society. He points out that that the volatility of Bitcoin imply that Bitcoin is subject to inflation.

Chohan (2017) highlights that the regulatory risks that Initial Coin Offering (ICO) causes participants. He suggests that there is a greater risk of fraud in ICOs than Bitcoin. ICOs require traditional regulation but bitcoin which is trust-less do not. He points out that in Hong Kong and New Zealand administer regular law on ICOs which works well. However, so does case-case approach as in Australia and US.

Keidar and Blemus (2018) is a short discussion paper on the need for cryptocurrencies regulation. The main market manipulation and insider trading regulation in the European Union is the Market Abuse Regulation No 596/2014. However, application of it in cryptocurrencies is limited.

Kaplanov (2012) study is grounded in law analysis and argues strongly against applying any regulation to bitcoin use. He highlights that it would be ineffective and contrary to the interest of the United States.

King (2015) presents a framework for financial institutions (FIs) to consider for managing the risks associated with banking Bitcoin-related businesses.

\subsection{Blockchains: Payments}

Berg, Davidson, and Potts (2017) use the transaction cost analysis developed by Oliver Williamson to understand the economic attributes of blockchain technology (blockchain consensus mechanism). Consensus mechanism is known as 'proof-ofwork'-rewards miners who compete to solve the puzzle. They investigate opportunism vs. trust. The paper suggests that blockchains are platforms for three-sided bargaining that convert energy-intensive computation into economically-valuable trust. Blockchains reduce opportunism costs that would prevent exchanges being 
undertaken.

MacDonald, Allen, and Potts (2016) analyse blockchains based on new institutional economics and public choice economics. They use New Institutional Economics (NIE) (Transaction Cost Economics (TCE)) for the analysis. The main argument of the paper is that blockchain competes with banks, enabling banking transactions to move from centralized hierarchical organizations to decentralized markets. The blockchain is a new institutional technology. They point out that blockchains are a new general purpose technology and a technology of decentralization. Blockchain makes possible new types of contracts, hence is a new institutional technology. This will lead to more 'evolvable efficient institutions of governance'.

Mainelli and Milne (2016) investigate three propositions about the impact of mutual distributed ledger technology on the post-trade processing global securities market. These include 1) access to the mutual distributed ledger, 2) piecemeal or big bang change, 3) implementation mutual distributed ledger in securities settlement would require major changes in business processes. Interviews and focus group meetings with professionals working in post-trade processing and mutual distributed ledger services are used for the analysis. The majority of the data was obtained in two focus group meetings held on 29 September 2015 and 25 November 2015 at the Z/Yen offices in London. Two general insights determined were 1) in a distributed ledgers world, the central third-party role would be confirming identity and dispute resolution, 2) distributed ledgers are a form of database technology. The research determines that use of blockchain to validate operational data in mutual distributed ledgers can reduce costs and risks. However, achieving all the benefits from mutual distributed ledgers will require time, resources, and active regulatory support for process reform.

Chapman et al. (2017) investigate whether distributed wholesale payment systems is practical. The suggest that Project Jaspar is a DLT-based wholesale 
payment system. The experiment can provide insights into the benefits and costs of using DLT for financial market infrastructures. Benefits of the financial system of a DLT-based wholesale payment system is due to interaction with a larger DLT ecosystem to financial market infrastructures. For wholesale payment, DLT may not provide benefit over centralised systems.

\subsection{Blockchain: Economics}

Abadi and Brunnermeier (2018) develop a ledger competition model to determine when it is more economical to use blockchain than a ledger managed by a centralized intermediary. This paper uses a static analysis to look at extraction of rents. However, extensions include a repeated setting and 'sufficient' decentralization of the network. Blockchain is more economically viable when users have incentives to abandon an established ledger in favour of a competitor.

Biais et al. (2018) model the proof-of-work blockchain protocol as a stochastic game and analyse the equilibrium strategies of rational, strategic miners. When miners benefit from coordinating on a single chain (maintaining consensus) coordination motives can lead to abandoning portions of the blockchain. Consequently, they argue blockchain may not be able to provide stable and immutable history of transactions.

Canidio (2018) studies a developer working on an open-source blockchain-based protocol that can be used only with a protocol-specific crypto-token. He shows that seignorage can generate incentives and provide capital for the development of the blockchain-based software.

Aune, O'Hara, and Slama (2017) argue that blockchain does not tackle the key problem facing traders of disguising their trades. This would still need to be done to keep other copying them or front-running the trades. The paper shows that information leakage can arise between when a transaction is published and 
the validation by miners. There is a limited priority in writing transactions to the distributed ledger. They propose a cryptology-based approach for solving information leakage problems in distributed ledgers. A mathematical identifier is used to secure time-priority.

Saleh (2017) develops an economic model of Proof-of-Stake (PoS) and shows that PoS induces consensus in equilibrium. Consensus results from the endogenous blockchain coin pricing in the model. He shows that consensus is almost inevitable in any equilibrium given blockchain employs a small block reward schedule. His theoretical model includes an extensive form game with periods, PoS protocol, a fork etc.

\subsection{Blockchains: Mathematics}

Lipton (2018) describes applications of blockchains (BC) and distributed ledgers (DL) to money and banking. The paper discusses historical examples of BC and DL such as in genealogical trees of royal and land titles. Potential usages of DLT in banking include 1) banking X-road, (analogy to the Estonian X-Road) 2) trade execution, clearing, settlement, 3) Global payments, trade finance, rehypothecation. He also compares the role of digital currencies in modern society with other forms of digital cash.

\subsection{Blockchains: Law}

Davidson, De Filippi, and Potts (2018) suggest that the impact of blockchain is not only a new general purpose technology but is an institutional technology. They argue that blockchains are an instance of institutional evolution. A new technology of governance.

De Filippi (2016) investigates whether Bitcoin and other blockchain-based networks is a decentralized infrastructure which suffers from transparency. The trans- 
parency problem is that individuals can obtain history of all transactions and potentially sensitive information about others. There is some benefit as individuals can transact with each other without disclosing identity. The paper concludes that cryptographic techniques can ensure transaction data remains confidential. In addition, users can uncloak their transaction data to a third party in a certified way.

De Filippi and Hassan (2018) argue that with blockchain code is having a stronger role in regulating individuals' interactions over the Internet. The paper's main argument is that there is a movement from the traditional notion of code having the effect of law to the new conception of law being defined as code. She describes four distinct phase, in the late 20th and early 21st century, that represent the relationship between law and technology. These include 1) first phase digitizing information, 2) second phase is bringing automation to decision-making processes, 3 ) third phase is incorporation of legal rules into code and the emergence of regulation by code, 4) fourth phase is code-ification of law.

Rohr and Wright (2017) suggest that SEC and Congress should provide token sellers and the exchanges with certainty of regulation (i.e., Howey test to digital tokens). Further they propose that lawmakers should provide belief that the public sale of such tokens is not a violation of Section 5 of the Securities Act of 1933.

Walch (2015) investigates whether Bitcoin blockchain is can be the foundation of financial market infrastructure including whether it is robust enough to be the base of payment, settlement, clearing and trading systems. She points out that Bitcoin as a software is vulnerable to attack, it has bugs and few people understand how it works. She concludes that operational risks make it unsuitable to serve as base of the financial system.

Werbach (2017) argues that potential of Bitcoin is extraordinary, but effective governance is critical to promote trust. This paper shows that blockchain-based 
systems can go wrong when they stray too far from legal enforcement. He concludes with excessive rigid legal obligations will hider innovations.

Finck (2017) investigates digital data-driven platforms and their impact on contemporary regulatory paradigms. The commission has assumed that selfregulation or co-regulation can replace top-down legislative intervention in the platform economy. However, the paper shows command-and-control regulation and self-regulation are problematic in platform application. Consequently,the best option is co-regulation.

Brito, Shadab, and Castillo (2014) highlight Bitcoin regulation will likely be aimed at financial instruments. They investigate the financial instruments (e.g. traditional securities and derivatives, new Bitcoin-denominated instruments, and decentralized markets and exchanges) that regulators will be most concerned with given the advent of blockchain technology and Bitcoin. They point out that the Commodity Exchange Act is unlikely to cover Bitcoin derivatives. In addition laws on online gambling will be problematic as they do not consider Bitcoin. They suggest given Financial Crimes Enforcement Network stance on virtual currencies regulators should exempt transactions denominated in Bitcoin. Policymakers should promote adaptation by existing institutions instead.

Goldenfein and Hunter (2017) describe a blockchain based system to solve the orphan works problem (i.e. users cannot license works and as a result may not use them). The proposal includes 1) mechanisms such as automated systems to perform diligent search of rights holder, 2) blockchain register of searches for which a works owner can be recorded, 3) legal mechanism to define works as orphanhood after search for a rights holder is deemed diligent. Although the exact design of regulation is a policy choice, the paper highlights the viability of technology in potential law. 


\subsection{Blockchain: Technology/Innovation}

Tasca (2016) is a descriptive piece in regards to Bitcoin as a payment network and as money. Blockchain-based payment network solutions provide a cheap and secured cross-border payment and settlement framework. Bitcoin is also a medium of exchange, a unit of account and store of value.

\subsection{Blockchain: Other}

Maurer (2016) argues that distributed ledgers do not only verify record transaction but also verify them without apparent human intercession. Blockchain has the potential to make paper-based records obsolete with transactions stored on the decentralised ledger. It can reduce error, improve efficiency and eliminate transactional risk. However, there are worries. Reducing latency, distributed ledgers could lead to the practices of before 2008 of making risk-stratified products. He discusses that blockchain's smart contract introduces economic agents that could be viewed as robots or legal individuals. They may have the same rights as a natural person.

Maurer, Nelms, and Swartz (2013) study the semiotics of Bitcoin. They use an archive of conversations for the investigation. Like other forms of money, Bitcoin is a promise. However, a different promise, a promise backed by an algorithm with expression in a digital peer-to-peer network.

Babich and Hilary (2018) investigate the implications of Blockchain technology for operations management (OM). They identify five key strengths, five main weakness, and three themes associated with Blockchain for OM. Blockchain technology five strengths are 1) visibility, 2) aggregation, 3) validation, 4) automation, and 5) resiliency. Blockchain five weaknesses are 1) the lack of standardization, 2) privacy concerns, 3) the black box effect, 4) inefficiency, and 5) the 'garbage in, garbage 
out' problem. The three themes -information, automation, and tokenization are research ideas for the future.

\section{Conclusion}

This paper has offered research agendas under seven gaps highlighted by our literature review and through discussions and focus groups with academics and policymakers. The seven gaps are 1) changing industrial structure and organisation of financial services, 2) new forms of financial intermediation (alternative finance) such as loan-based and equity-based crowdfunding, 3) changing payments mechanisms including central bank digital currencies and the shift to a cashless society, 4) reaching vulnerable and excluded customers in both developed and developing countries, 5) computation, artificial intelligence and large-scale data processing in finance, 6) the relationship between the new financial technologies and financial regulation, 7) identity, security, data privacy and their regulation in financial services.

Some of the gaps have been researched more than others. For instance there is work in relation to 2) new forms of financial intermediation (alternative finance) such as loan-based and equity-based crowdfunding. On the other hand, there is almost no studies in regards to 7) and 5). However, in all the gaps, there is much more to be done. Current research is loosely connected with no overall research agenda. Our aim is to provide coherent research agendas that can be the foundation of future academic work in this area. We feel that by addressing these gaps this field will become an established academic discipline. 


\section{References}

Abadi, Joseph, and Markus Brunnermeier. 2018. "Blockchain Economics." https: //scholar.princeton.edu/markus/publications/blockchain-economics.

Accenture. 2018. Global Venture Capital Investment in Fintech Industry Set Record in 2017. https: / / newsroom . accenture . com / news / global - venture capital - investment - in - fintech - industry - set - record - in - 2017 driven-by-surge-in-india-us-and-uk-accenture-analysis-finds . htm.

Acemoglu, Daron, Asuman Ozdaglar, and Alireza Tahbaz-Salehi. 2015. "Systemic risk and stability in financial networks." American Economic Review 105 (2): $564-608$.

Agarwal, Ruchir. 2015. Breaking through the zero lower bound. International Monetary Fund.

Agrawal, Ajay, Christian Catalini, and Avi Goldfarb. 2011. The geography of crowdfunding. Technical report. National bureau of economic research.

. 2014. "Some simple economics of crowdfunding." Innovation Policy and the Economy 14 (1): 63-97.

Ahlers, Gerrit KC, Douglas Cumming, Christina Günther, and Denis Schweizer. 2015. "Signaling in equity crowdfunding." Entrepreneurship Theory and Practice 39 (4): 955-980.

Arner, Douglas W, Janos Nathan Barberis, and Ross P Buckley. 2015. "The evolution of Fintech: A new post-crisis paradigm." Geo. J. Int'l L. 47:1271.

2016a. "FinTech, RegTech, and the Reconceptualization of Financial Regulation." Nw. J. Int'l L. \& Bus. 37:371. 
Arner, Douglas W, Janos Nathan Barberis, and Ross P Buckley. 2016b. "The emergence of regtech 2.0: from know your customer to know your data." https : //www . researchgate. net/publication/313365398_The_Emergence_of _ Regtech_20_From_Know_Your_Customer_to_Know_Your_Data.

Arvidsson, Niklas. 2018. "The future of cash." In The Rise and Development of FinTech, 107-120. Routledge.

Athey, Susan, Christian Catalini, and Catherine Tucker. 2017. The digital privacy paradox: small money, small costs, small talk. Technical report. National Bureau of Economic Research.

Aune, Rune Tevasvold, Maureen O'Hara, and Ouziel Slama. 2017. "Footprints on the Blockchain: Information Leakage in Distributed Ledgers." http://jot . iijournals.com/content/12/3/5.

Babich, Volodymyr, and Gilles Hilary. 2018. "What OM Researchers Should Know About Blockchain Technology." https://papers.ssrn.com/sol3/papers . cfm?abstract_id=3131250.

Bank for International Settlements. 2018. Implications of fintech developments for banks and bank supervisor. https://www. bis.org/bcbs/publ/d431.pdf.

Barrdear, John, and Michael Kumhof. 2016. "The macroeconomics of central bank issued digital currencies." https : //www . bankofengland . co . uk/workingpaper/2016/the-macroeconomics-of-central-bank-issued-digitalcurrencies.

Baxter, Lawrence G. 2016. "Adaptive financial regulation and regtech: a concept article on realistic protection for victims of bank failures." Duke LJ 66:567. 
Belleflamme, Paul, Thomas Lambert, and Armin Schwienbacher. 2014. "Crowdfunding: Tapping the right crowd." Journal of business venturing 29 (5): 585609 .

Benos, Evangelos, Rod Garratt, and Pedro Gurrola-Perez. 2017. "The economics of distributed ledger technology for securities settlement." https : / / ww . bankofengland.co.uk/working-paper/2017/the-economics-of-distributedledger-technology-for-securities-settlement.

Bentov, Iddo, Yan Ji, Fan Zhang, Yunqi Li, Xeuyuan Zhao, Lorenz Breidenbach, Philip Daian, and Ari Juels. 2017. Tesseract: Real-time cryptocurrency exchange using trusted hardware.

Berg, Chris, Sinclair Davidson, and Jason Potts. 2017. "Blockchains industrialise trust." https : / / papers . ssrn . com / sol3/papers . cfm? abstract_ id= 3074070 .

Biais, Bruno, Christophe Bisiere, Matthieu Bouvard, and Catherine Casamatta. 2018. "The blockchain folk theorem." https ://papers. ssrn. com/sol3/ papers.cfm?abstract_id=3108601.

Bianchi, Daniele. 2017. "Cryptocurrencies as an Asset Class: An Empirical Assessment." https ://papers.ssrn.com/sol3/papers.cfm?abstract_id= 3077685 .

Bjerg, Ole. 2017. "Designing new money-the policy trilemma of central bank digital currency." https : //papers.ssrn. com/sol3/papers.cfm?abstract_id= 2985381.

Bolt, Wilko, and Maarten RC van Oordt. 2016. "On the value of virtual currencies." https://ideas.repec.org/p/dnb/dnbwpp/521.html. 
Bordo, Michael D, and Andrew T Levin. 2017. Central bank digital currency and the future of monetary policy. Technical report. National Bureau of Economic Research.

Borge, Maria, Eleftherios Kokoris-Kogias, Philipp Jovanovic, Linus Gasser, Nicolas Gailly, and Bryan Ford. 2017. "Proof-of-Personhood: Redemocratizing Permissionless Cryptocurrencies." In Security and Privacy Workshops (EuroSEPW), 2017 IEEE European Symposium on, 23-26. IEEE.

Bouoiyour, Jamal, and Refk Selmi. 2017. "The Bitcoin price formation: Beyond the fundamental sources." arXiv preprint arXiv:170\%.01284.

Brito, Jerry, Houman Shadab, and Andrea Castillo. 2014. "Bitcoin financial regulation: Securities, derivatives, prediction markets, and gambling." Colum. Sci. \&6 Tech. L. Rev. 16:144.

Brummer, Chris, and Yesha Yadav. 2017. "The Fintech Trilemma." https : / / papers.ssrn.com/sol3/papers.cfm?abstract_id=3054770.

Buchak, Greg, Gregor Matvos, Tomasz Piskorski, and Amit Seru. 2017. Fintech, regulatory arbitrage, and the rise of shadow banks. Technical report. National Bureau of Economic Research.

Callesen, Per. 2017. Can banking be sustainable in the future? A perspective from Danmarks Nationalbank. https://www.bis.org/review/r171031c.htm.

Canidio, Andrea. 2018. "Financial incentives for open source development: the case of Blockchain." https://mpra.ub.uni-muenchen.de/85352/.

Catalini, Christian, and Joshua S Gans. 2018. Initial coin offerings and the value of crypto tokens. Technical report. National Bureau of Economic Research. 
Chakraborty, Chiranjit, and Andreas Joseph. 2017. "Machine learning at central banks." https://ideas.repec.org/p/boe/boeewp/0674.html.

Chan, Ka Kei, and Alistair Milne. 2013. "The Global Legal Entity Identifier System: Will it Deliver?" https : / / papers . ssrn . com/sol3/papers . cfm? abstract_id=2325889.

Chapman, James, Rodney Garratt, Scott Hendry, Andrew McCormack, and Wade McMahon. 2017. "Project Jasper: are distributed wholesale payment systems feasible yet?" Financial System. https : / / www . semanticscholar . org / paper / Project - Jasper \% 3A - Are - Distributed - Wholesale - Payment Chapman-Garratt/0dbd3790b52cf73a75626247b8465c4f4f16177c.

Cheah, Eng-Tuck, and John Fry. 2015. "Speculative bubbles in Bitcoin markets? An empirical investigation into the fundamental value of Bitcoin." Economics Letters 130:32-36.

Chellappa, Ramnath K, and Paul A Pavlou. 2002. "Perceived information security, financial liability and consumer trust in electronic commerce transactions." Logistics Information Management 15 (5/6): 358-368.

Chemla, Gilles, and Katrin Tinn. 2017. "Learning through crowdfunding." https: //papers.ssrn.com/sol3/papers.cfm?abstract_id=2796435.

Chiu, Jonathan, and Thorsten V Koeppl. 2017. "The economics of cryptocurrenciesbitcoin and beyond." https ://www . chapman . edu/research/institutes and-centers/economic-science-institute/_files/ifree-papers-andphotos/koeppel-april2017.pdf.

Chohan, Usman. 2017. "Initial Coin Offerings (ICOs): Risks, Regulation, and Accountability." https://papers.ssrn.com/sol3/papers.cfm?abstract_id= 3080098 . 
Cholakova, Magdalena, and Bart Clarysse. 2015. "Does the possibility to make equity investments in crowdfunding projects crowd out reward-based investments?" Entrepreneurship Theory and Practice 39 (1): 145-172.

Chuang, Li-Min, Chun-Chu Liu, and Hsiao-Kuang Kao. 2016. "The adoption of fintech service: TAM perspective." Int J Manag Adm Sci 3:1-15.

Colombo, Massimo G, Chiara Franzoni, and Cristina Rossi-Lamastra. 2015. "Internal social capital and the attraction of early contributions in crowdfunding." Entrepreneurship Theory and Practice 39 (1): 75-100.

Constâncio, Vitor. 2017. "The future of finance and the outlook for regulation." In remarks at the Financial Regulatory Outlook Conference, Rome, vol. 9.

Cumming, Douglas J, and Armin Schwienbacher. 2016. "Fintech venture capital." https://papers.ssrn.com/sol3/papers.cfm?abstract_id=2784797.

Danielsson, Jon. 2017. Artificial intelligence and the stability of markets. [Online; accessed 14-May-2018]. https : / / voxeu .org/article/artificialintelligence-and-stability-markets.

Danielsson, Jon, Robert Macrae, and Andreas Uthemann. 2017. Artificial intelligence, financial risk management and systemic risk. Technical report. London School of Economics, SRC Special Paper No 13.

Davidson, Sinclair, Primavera De Filippi, and Jason Potts. 2018. "Blockchains and the economic institutions of capitalism." Journal of Institutional Economics: $1-20$.

De Filippi, Primavera. 2016. "The interplay between decentralization and privacy: the case of blockchain technologies." https : / / papers . ssrn . com/sol3 / papers. cfm?abstract_id=2852689. 
De Filippi, Primavera, and Samer Hassan. 2018. "Blockchain technology as a regulatory technology: From code is law to law is code." arXiv preprint arXiv:1801.0250\%.

Deloitte. 2017. Managing conduct risk: Addressing drivers, restoring trust. https: / / www2 . deloitte . com / content / dam / Deloitte / global / Documents / Financial-Services/gx-financial-services-managing-conduct-povnew.pdf.

Dhar, Vasant, and Roger M Stein. 2016. "FinTech Platforms and Strategy." https: //papers.ssrn.com/sol3/papers.cfm?abstract_id=2892098.

Dorfleitner, Gregor, Lars Hornuf, Matthias Schmitt, and Martina Weber. 2017. "The FinTech Market in Germany." In FinTech in Germany, 13-46. Springer.

Duff\&Phelps. 2018. Too Much of a Good Thing. https://www .duffandphelps . com/insights/publications/compliance-and-regulatory-consulting/ global-regulatory-outlook-2018/too-much-of-a-good-thing.

Dwyer, Gerald P. 2015. "The economics of Bitcoin and similar private digital currencies." Journal of Financial Stability 17:81-91.

Elliott, Karen, Fabio Massacci, Chan-Nam Ngo, and Julian M Williams. 2016. "Unruly Innovation: Distributed Ledgers, Blockchains and the Protection of Transactional Rents." https : // papers . ssrn . com / sol3/papers . cfm? abstract_id=2888872.

Enriques, Luca. 2017. "Financial supervisors and Regtech: Four roles and four challenges." https://papers.ssrn.com/sol3/papers.cfm?abstract_id= 3087292 . 
Eyal, Ittay, and Emin Gün Sirer. 2014. "Majority is not enough: Bitcoin mining is vulnerable." In International conference on financial cryptography and data security, 436-454. Springer.

Faia, Ester, and Monica Paiella. 2018. "P2P Lending: Information Externalities, Social Networks and Loans' Substitution." https : / / papers . ssrn . com / sol3/papers.cfm?abstract_id=3028601.

Figà-Talamanca, Gianna, and Marco Patacca. 2018. "Does Market Attention Affect Bitcoin Returns and Volatility?" https : / / papers . ssrn . com/so13/ papers.cfm?abstract_id=3148018.

Financial Stability Board. 2017. "Financial Stability Implications from FinTech: Supervisory and Regulatory Issues that Merit Authorities' Attention." Financial Stability Board. http://www.fsb.org/2017/06/financial-stabilityimplications-from-fintech/.

Finck, Michèle. 2017. "Digital Regulation: Designing a Supranational Legal Framework for the Platform Economy." http://eprints.1se.ac.uk/87568/.

FirstRand Bank. 2016. The Advent of Crypto Banking: A New Paradigm for Central and Commercial Banking. https://www.foundery.co.za/wp-content/ uploads/2017/09/The_Advent_of_Crypto_Banking.pdf.

Foley, Sean, Jonathan Karlsen, and Tālis J Putniņš. 2018. "Sex, Drugs, and Bitcoin: How Much Illegal Activity is Financed Through Cryptocurrencies?" https://papers.ssrn.com/sol3/papers.cfm?abstract_id=3102645.

Freedman, Seth, and Ginger Zhe Jin. 2017. "The information value of online social networks: lessons from peer-to-peer lending." International Journal of Industrial Organization 51:185-222. 
Freji, Ake. 2018. "A regulatory innovation framework: How regulatory change leads to innovation outcomes for Fintechs." In The Rise and Development of FinTech, 23-42. Routledge.

Fung, Ben SC, and Hanna Halaburda. 2016. "Central bank digital currencies: a framework for assessing why and how." https : / /www. bankofcanada.ca/ 2016/11/staff-discussion-paper-2016-22/.

Gabor, Daniela, and Sally Brooks. 2017. "The digital revolution in financial inclusion: international development in the fintech era." New Political Economy 22 (4): $423-436$.

Gandal, Neil, and Hanna Halaburda. 2016. "Can we predict the winner in a market with network effects? Competition in cryptocurrency market." Games 7 (3): 16.

Gandal, Neil, JT Hamrick, Tyler Moore, and Tali Oberman. 2018. "Price manipulation in the Bitcoin ecosystem." Journal of Monetary Economics.

Garratt, Rod. 2016. "CAD-coin versus Fedcoin.” R3 Report 15.

Garratt, Rodney, and Neil Wallace. 2018. "Bitcoin 1, Bitcoin 2,...: An experiment in privately issued outside monies." Economic Inquiry. https ://onlinelibrary . wiley.com/doi/abs/10.1111/ecin. 12569.

Gelb, Alan. 2016. "Balancing Financial Integrity with Financial Inclusion: The risk-based approach to 'Know your customer'." CGD Policy Paper 74.

Gervais, Arthur, Hubert Ritzdorf, Ghassan O Karame, and Srdjan Capkun. 2015. "Tampering with the delivery of blocks and transactions in bitcoin." In Proceedings of the 22nd ACM SIGSAC Conference on Computer and Communications Security, 692-705. ACM. 
Goldenfein, Jake, and Dan Hunter. 2017. "Blockchains, Orphan Works, and the Public Domain." https://lawandarts .org/article/blockchains-orphanworks-and-the-public-domain/.

Golumbia, David. 2016. The politics of Bitcoin: software as right-wing extremism. University of Minnesota Press.

Gomber, Peter, Robert J Kauffman, Chris Parker, and Bruce W Weber. 2018. "On the Fintech Revolution: Interpreting the Forces of Innovation, Disruption, and Transformation in Financial Services." Journal of Management Information Systems 35 (1): 220-265.

Gouveia, Olga Cerqueira, Enestor Dos Santos, Santiago Fernández de Lis, Alejandro Neut, Javier Sebastián, et al. 2017. Central Bank Digital Currencies: assessing implementation possibilities and impacts. Technical report. https: //ideas.repec.org/p/bbv/wpaper/1704.html.

Gozman, Daniel, Jonathan Liebenau, and Jonathan Mangan. 2018. "The Innovation Mechanisms of Fintech Start-Ups: Insights from SWIFTs Innotribe Competition." Journal of Management Information Systems 35 (1): 145-179.

Gulamhuseinwala, Imran, Thomas Bull, and Steven Lewis. 2015. "FinTech is gaining traction and young, high-income users are the early adopters." https: //papers.ssrn.com/sol3/papers.cfm?abstract_id=3083976.

Haddad, Christian, and Lars Hornuf. 2016. "The emergence of the global fintech market: Economic and technological determinants." https://papers.ssrn . com/sol3/papers.cfm?abstract_id=2830124.

Hallberg, Matthias, and Bjorn Olsson. 2018. "Fintech in Sweden: Will policymakers (in) action nurture or starve its growth?" In The Rise and Development of FinTech, 66-84. Routledge. 
Harvey, Campbell. 2016. "Cryptofinance." https : //papers . ssrn . com/sol3/ Papers.cfm?abstract_id=2438299.

Havrylchyk, Olena, Carlotta Mariotto, Talal-Ur Rahim, and Marianne Verdier. 2017. "What drives the expansion of the peer-to-peer lending?" https : / / papers.ssrn.com/sol3/papers. cfm?abstract_id=2841316.

Heilman, Ethan, Alison Kendler, Aviv Zohar, and Sharon Goldberg. 2015. "Eclipse Attacks on Bitcoin's Peer-to-Peer Network." In USENIX Security Symposium, $129-144$.

Hendrickson, Joshua R, Thomas L Hogan, and William J Luther. 2016. "The political economy of bitcoin." Economic Inquiry 54 (2): 925-939.

Hendry, Scott, and Yu Zhu. 2017. "A framework for analyzing monetary policy in an economy with E-money." https:// editorialexpress .com/cgibin/conference/download.cgi?db_name=mmmspr2017\&paper_id=104.

Henry, Christopher S, Kim P Huynh, Gradon Nicholls, et al. 2017. Bitcoin Awareness and Usage in Canada. Bank of Canada. https://www . bankof canada. ca/wp-content/uploads/2017/12/swp2017-56.pdf.

Hileman, Dr Garrick, and Michel Rauchs. 2017. "2017 Global Cryptocurrency Benchmarking Study." https : //papers . ssrn . com/sol3/papers . cfm? abstract_id=2965436.

Hileman, Garrick. 2015. "The bitcoin market potential index." In International Conference on Financial Cryptography and Data Security, 92-93. Springer.

Holden, Richard, and Anup Malani. 2017. "Can Blockchain Solve the Holdup Problem in Contracts?" https : //papers . ssrn . com/sol3/papers . cfm? abstract_id=3093879. 
Hornuf, Lars, and Armin Schwienbacher. 2017. "Should securities regulation promote equity crowdfunding?" Small Business Economics 49 (3): 579-593.

Houstoun, Kevin, Alistair Milne, and Paul Parboteeah. 2015. "Preliminary report on standards in global financial markets." https://papers.ssrn.com/sol3/ papers.cfm?abstract_id=2531210.

Huberman, Gur, Jacob D Leshno, and Ciamac C Moallemi. 2017. "Monopoly without a monopolist: An economic analysis of the bitcoin payment system." https://moallemi.com/ciamac/papers/bitcoin-2017.pdf.

Iyer, Rajkamal, Asim Ijaz Khwaja, Erzo FP Luttmer, and Kelly Shue. 2009. "Screening in new credit markets: Can individual lenders infer borrower creditworthiness in peer-to-peer lending?" https : //papers . ssrn . com/sol3/ papers.$c f m$ ?abstract_id=1570115\&rec $=1 \& \operatorname{srcabs}=1114428 \& a l g=1 \& p o s=$ 10.

Jagtiani, Julapa, and Catharine Lemieux. 2016. "Small business lending: challenges and opportunities for community banks." https://papers.ssrn.com/sol3/ papers. cfm?abstract_id=2752863.

2017. "Fintech Lending: Financial Inclusion, Risk Pricing, and Alternative Information." https://papers.ssrn.com/sol3/papers.cfm?abstract_id= 3005260 .

2018. "Do Fintech Lenders Penetrate Areas That Are Underserved by Traditional Banks?" Journal of Economics and Business.

Jagtiani, Julapa, Catharine Lemieux, et al. 2018. The Roles of Alternative Data and Machine Learning in Fintech Lending: Evidence from the LendingClub Consumer Platform. Technical report. https: //papers. ssrn . com/sol3/ papers. cfm?abstract_id=3178461. 
Jagtiani, Julapa, Larry Wall, and Todd Vermilyea. 2018. "The Roles of Big Data and Machine Learning in Bank Supervision." https ://www . theclearinghouse. org / banking - perspectives / 2018 / 2018 - q1 - banking - perspectives / articles/big-data-ml-bank-supervision.

Jiang, Yang, Yi-Chun Ho, Xiangbin Yan, and Yong Tan. 2018. "Investor Platform Choice: Herding, Platform Attributes, and Regulations." Journal of Management Information Systems 35 (1): 86-116.

Johnson, Michael A, Regan M Stevenson, and Chaim R Letwin. 2018. "A woman's place is in the...startup! Crowdfunder judgments, implicit bias, and the stereotype content model." Journal of Business Venturing.

Jonsdottir, F, O Toivonen, V Jaatinen, Utti A, and R Lindqvist. 2017. "FinTech in the Nordic: A Deloitte review." Deloitte review.

Kahn, Charles, Francisco Rivadeneyra, and Tsz-Nga Wong. 2018. "E-money and Payments Policy." https://www. bankofcanada.ca/profile/franciscorivadeneyra/.

Kaplanov, Nikolei. 2012. "Nerdy money: Bitcoin, the private digital currency, and the case against its regulation." Loy. Consumer L. Rev. 25:111.

Kareken, John, and Neil Wallace. 1981. "On the indeterminacy of equilibrium exchange rates." The Quarterly Journal of Economics 96 (2): 207-222.

Karkkainen, Tatja, Georgios A Panos, Daniel Broby, and Andrea Bracciali. 2017. "On the educational curriculum in finance and technology." In International Conference on Internet Science, 7-20. Springer. 
Kazan, Erol, Chee-Wee Tan, Eric TK Lim, Carsten Sørensen, and Jan Damsgaard. 2018. "Disentangling digital platform competition: The case of UK mobile payment platforms." Journal of Management Information Systems 35 (1): 180-219.

Keidar, Roy, and Stéphane Blemus. 2018. "Cryptocurrencies and Market Abuse Risks: It's Time for Self-Regulation." IDC Herzliyah.

Ketterer, Juan Antonio, and Gabriela Andrade. 2016. Digital Central Bank Money and the Unbundling of the Banking Function. Technical report. Inter-American Development Bank. https : / / publications . iadb . org/handle / 11319 / 7587.

Kim, Yonghee, Young-Ju Park, Jeongil Choi, and Jiyoung Yeon. 2016. "The adoption of mobile payment services for Fintech." International Journal of Applied Engineering Research 11 (2): 1058-1061.

King, Douglas. 2015. "Banking Bitcoin-Related Businesses: A Primer for Managing BSA/AML Risks." In Retail Payment Risks Forum Working Paper. Federal Reserve Bank of Atlanta.

Kogias, Eleftherios Kokoris, Philipp Jovanovic, Nicolas Gailly, Ismail Khoffi, Linus Gasser, and Bryan Ford. 2016. "Enhancing bitcoin security and performance with strong consistency via collective signing." In 25th USENIX Security Symposium (USENIX Security 16), 279-296.

Kumhof, Michael, Clare Noone, et al. 2018. Central bank digital currencies-design principles and balance sheet implications. Technical report. Bank of England.

Lacasse, RM, BA Lambert, N Roy, J Sylvain, and F Nadeau. 2016. "A Digital Tsunami: FinTech and Crowdfunding." In International Scientific Conference on Digital Intelligence. April, 4-6. 
Lai, Rose Neng, and Robert Van Order. 2017. "Fintech Finance and Financial Fragility:Focusing on China." https://www.researchgate.net/publication/ 321185322_Fintech_Finance_and_Financial_Fragility-Focusing_on_ China.

Leong, Carmen, Barney Tan, Xiao Xiao, Felix Ter Chian Tan, and Yuan Sun. 2017. "Nurturing a FinTech ecosystem: The case of a youth microloan startup in China." International Journal of Information Management 37 (2): 92-97.

Lewan, Mats. 2018. "The role of trust in emerging technologies." In The Rise and Development of FinTech, 111-129. Routledge.

Li, Jiasun, and William Mann. 2018. "Initial coin offering and platform building." https://papers.ssrn.com/sol3/papers.cfm?abstract_id=3088726.

Liebergen, Bart van, et al. 2017. "Machine learning: A revolution in risk management and compliance?" Journal of Financial Transformation 45:60-67.

Lin, Mingfeng, Nagpurnanand R Prabhala, and Siva Viswanathan. 2009. "Judging borrowers by the company they keep: Social networks and adverse selection in online peer-to-peer lending." https://papers.ssrn.com/sol3/papers . cfm?abstract_id=1355679.

Lipton, Alexander. 2018. "Blockchains and distributed ledgers in retrospective and perspective." The Journal of Risk Finance 19 (1): 4-25.

Lootsma, YVONNE. 2017. "From Fintech To Regtech: The Possible Use Of Blockchain For Kyc." Fintech To Regtech Using block chain.

MacDonald, Trent J, Darcy WE Allen, and Jason Potts. 2016. "Blockchains and the boundaries of self-organized economies: Predictions for the future of banking." In Banking Beyond Banks and Money, 279-296. Springer. 
Mach, Traci, Courtney Carter, and Cailin Slattery. 2014. "Peer-to-peer lending to small businesses." Federal Reserve Board of Governors, Finance and Economics Discussion Series 2014-10.

Mai, Feng, Zhe Shan, Qing Bai, Xin Wang, and Roger HL Chiang. 2018. "How does social media impact Bitcoin value? A test of the silent majority hypothesis." Journal of Management Information Systems 35 (1): 19-52.

Mainelli, Michael, and Alistair Milne. 2016. "The impact and potential of blockchain on securities transaction lifecycle." https : / / papers . ssrn . com / sol3 / papers.cfm?abstract_id=2777404.

Malinova, Katya, and Andreas Park. 2017. "Market Design with Blockchain Technology." https : //papers . ssrn . com/sol3/papers . cfm? abstract_id= 2785626 .

Maurer, Bill. 2016. "Re-risking in Realtime. On Possible Futures for Finance after the Blockchain." Behemoth-A Journal on Civilisation 9 (2): 82-96.

Maurer, Bill, Taylor C Nelms, and Lana Swartz. 2013. "When perhaps the real problem is money itself!': the practical materiality of Bitcoin." Social Semiotics 23 (2): 261-277.

Meaning, Jack, Ben Dyson, James Barker, Emily Clayton, et al. 2018. Broadening narrow money: monetary policy with a central bank digital currency. Technical report. Bank of England. https : //www . bankofengland . co.uk/workingpaper / 2018 / broadening - narrow - money - monetary - policy - with - a central-bank-digital-currency.

Micheler, Eva, and Anna Whaley. 2018. "Regulatory Technology." https : / / papers.ssrn.com/sol3/papers. cfm?abstract_id=3164258. 
Miller, Andrew, and Iddo Bentov. 2017. "Zero-collateral lotteries in bitcoin and ethereum." In Security and Privacy Workshops (EuroS\&PW), 2017 IEEE European Symposium on, 4-13. IEEE.

Mills, David C, Kathy Wang, Brendan Malone, Anjana Ravi, Jeffrey C Marquardt, Anton I Badev, Timothy Brezinski, Linda Fahy, Kimberley Liao, Vanessa Kargenian, et al. 2016. "Distributed ledger technology in payments, clearing, and settlement." https://www. federalreserve.gov/econresdata/feds / 2016/files/2016095pap.pdf].

Milne, Alistair. 2017. "Cryptocurrencies from an Austrian perspective." https: //papers.ssrn.com/sol3/papers.cfm?abstract_id=2946160.

2018a. "Marketplace lending: business models and regulation in Australia and the UK."

—. 2018b. "State issued digital currencies: minor innovation or radical reform?"

Milne, Alistair, and Malcolm Chisholm. 2013. "The Prospects for Common Financial Language in Wholesale Financial Services." https://papers.ssrn.com/ sol3/papers.cfm?abstract_id=2325362.

Milne, Alistair, and Paul Parboteeah. 2015. "Expert Opinion on Standards in Global Financial Markets." https://papers.ssrn.com/sol3/papers.cfm? abstract_id=2605192.

. 2016. "The business models and economics of peer-to-peer lending." https : //www. ceps . eu/system/files/ECRI\%20RR17\%20P2P\%20Lending.pdf. 
Minto, Andrea, Moritz Voelkerling, and Melanie Wulff. 2017. "Separating apples from oranges: identifying threats to financial stability originating from FinTech." Capital Markets Law Journal 12 (4): 428-465.

Moss, Todd W, Donald O Neubaum, and Moriah Meyskens. 2015. "The effect of virtuous and entrepreneurial orientations on microfinance lending and repayment: A signaling theory perspective." Entrepreneurship Theory and Practice 39 (1): 27-52.

Nayak, Kartik, Srijan Kumar, Andrew Miller, and Elaine Shi. 2016. "Stubborn mining: Generalizing selfish mining and combining with an eclipse attack." In Security and Privacy (EuroSEPP), 2016 IEEE European Symposium on, 305320. IEEE.

Odinet, Christopher K. 2018. "Consumer Bitcredit and Fintech Lending." https: //papers.ssrn.com/sol3/papers.cfm?abstract_id=2949456.

Østbye, Peder. 2018. "Will Regulation Change Cryptocurrency Protocols?" https: //papers.ssrn.com/sol3/papers.cfm?abstract_id=3159479.

Packin, Nizan Geslevich. 2018. "RegTech, Compliance and Technology Judgment Rule." Chi.-Kent L. Rev. 93:193.

Parlour, Christine A, Uday Rajan, and Johan Walden. 2016. "Making Money: Commercial Banks, Liquidity Transformation and the Payment System." https: //papers.ssrn.com/sol3/papers.cfm?abstract_id=2892150.

Philippon, Thomas. 2015. "Has the US finance industry become less efficient? On the theory and measurement of financial intermediation." American Economic Review 105 (4): 1408-38. 
Philippon, Thomas. 2016a. "Finance, productivity, and distribution." https:// www . brookings . edu/wp-content/uploads/2018/01/philippon-october2016.pdf.

— 2016b. The fintech opportunity. Technical report. National Bureau of Economic Research.

Pieters, Gina. 2016. "Bitcoin Reveals Exchange Rate Manipulation and Detects Capital Controls." https : / / ideas . repec . org/p/ jmp/ jm2017 / ppi307 . html.

2017. "The Potential Impact of Decentralized Virtual Currency on Monetary Policy." https://papers.ssrn.com/sol3/papers.cfm?abstract_id= 2976515.

Pieters, Gina, and Sofia Vivanco. 2017. "Financial regulations and price inconsistencies across Bitcoin markets." Information Economics and Policy 39:114.

Prat, Julien, Walter Benjamin, et al. n.d. An Equilibrium Model of the Market for Bitcoin Mining. Technical report. https://ideas.repec.org/p/ces/ ceswps/_6865.html.

PWC. Redrawing the Lines: FinTechs Growing Influence on Financial Services.

Rau, P Raghavendra. 2017. "Law, trust, and the development of crowdfunding." https://papers.ssrn.com/sol3/papers.cfm?abstract_id=2989056.

Rauchs, Michel. 2016. "Cryptocurrencies meeting Business Ecosystems: The case of Bitcoin." PhD diss., Grenoble Ecole de Management. 
Reyes, Carla L. 2016. "Moving beyond bitcoin to an endogenous theory of decentralized ledger technology regulation: an initial proposal." Vill. L. Rev. 61:191.

Rohr, Jonathan, and Aaron Wright. 2017. "Blockchain-Based Token Sales, Initial Coin Offerings, and the Democratization of Public Capital Markets." https: //papers.ssrn.com/sol3/papers.cfm?abstract_id=3048104.

Saleh, Fahad. 2017. Blockchain Without Waste: Proof-of-Stake. Technical report. working paper. https://www . semanticscholar.org/paper/BlockchainWithout-Waste $\% 3 \mathrm{~A}$ - Proof - of - Stake $\% \mathrm{EF} \% \mathrm{BF} \% \mathrm{BD} \% \mathrm{EF} \% \mathrm{BF} \% \mathrm{BD} \% \mathrm{EF} \% \mathrm{BF} \% \mathrm{BD}$ Saleh/cd35131e29c6122dbacdb95d569be5b391da083a.

Schilling, Linda, and Harald Uhlig. 2018. Some Simple Bitcoin Economics. Technical report. National Bureau of Economic Research.

Schindler, John W. 2017. "FinTech and financial innovation: Drivers and depth." https : //www . federalreserve gov/econres/feds/files/2017081pap . $\operatorname{pdf}$.

Schwienbacher, Armin, and Benjamin Larralde. 2010. "Crowdfunding of small entrepreneurial ventures." https : //papers. ssrn . com/sol3/papers.cfm? abstract_id=1699183.

Shim, Yongwoon, and Dong-Hee Shin. 2016. "Analyzing China fintech industry from the perspective of actor network theory." Telecommunications Policy 40 (2-3): 168-181.

Siddik, Md Nur Alam, Gang Sun, CUI Yanjuan, and Sajal Kabiraj. 2014. "Financial Inclusion through Mobile Banking: A Case of Bangladesh." Journal of Applied Finance and Banking 4 (6): 109. 
Tasca, Paolo. 2016. "The dual nature of bitcoin as payment network and money." https://papers.ssrn.com/sol3/papers. cfm?abstract_id=2805003.

Treleaven, Philip. 2015. "Financial regulation of FinTech." https : // papers . ssrn.com/sol3/papers.cfm?abstract_id=3084015.

Treleaven, Philip, Bogdan Batrinca, et al. 2017. "Algorithmic regulation: automating financial compliance monitoring and regulation using AI and blockchain." Journal of Financial Transformation 45:14-21.

Tsai, Chang-Hsien, and Peng Kuan-Jung. 2017. "The FinTech Revolution and Financial Regulation: The Case of Online Supply-Chain Financing." Asian Journal of Law and Society 4 (1): 109-132.

Van Alstyne, Marshall W, Geoffrey G Parker, and Sangeet Paul Choudary. 2016. "Pipelines, platforms, and the new rules of strategy." Harvard Business Review 94 (4): 54-62.

Van Loo, Rory. 2017. "Making FinTech more competitive." https : //papers . ssrn. com/sol3/papers. cfm?abstract_id=2966890.

Villeroy de Galhau, F, et al. 2016. "Constructing the possible trinity of innovation, stability and regulation for digital finance." Financial Stability Review, no. 20: $5-13$.

Vismara, Silvio. 2016. "Equity retention and social network theory in equity crowdfunding." Small Business Economics 46 (4): 579-590.

Walch, Angela. 2015. "The bitcoin blockchain as financial market infrastructure: A consideration of operational risk." NYUJ Legis. \& Pub. Pol'y 18:837. 
Wardrop, Robert, Bryan Zhang, Raghavendra Rau, and Mia Gray. 2015. "Moving mainstream." The European Alternative Finance Benchmarking Report: 1516.

Weber, Rolf H, et al. 2017. "Regtech as a new legal challenge." Journal of Financial Transformation 46:10-17.

Werbach, Kevin D. 2017. "Trust, But Verify: Why the Blockchain Needs the Law." Social Science Research Network, Rochester, NY. Retrieved September 16:2017.

Wonglimpiyarat, Jarunee. 2018. "Challenges and dynamics of FinTech crowd funding: An innovation system approach." The Journal of High Technology Management Research.

Xu, Jennifer J, and Michael Chau. 2018. "Cheap Talk? The Impact of LenderBorrower Communication on Peer-to-Peer Lending Outcomes." Journal of Management Information Systems 35 (1): 53-85.

Yermack, David. 2015. "Is Bitcoin a real currency? An economic appraisal." In Handbook of digital currency, 31-43. Elsevier.

2017. "Corporate governance and blockchains." Review of Finance 21 (1): $7-31$.

Zhang, Fan, Philip Daian, and Gabriel Kaptchuk. 2018. "Paralysis Proofs: Secure Dynamic Access Structures for Cryptocurrencies and More." https : //eprint.iacr.org/2018/096.pdf. 